\title{
A Theoretical Study on Molten Alkali Carbonate Interfaces
}

\author{
Alberto Gutiérrez, ${ }^{a, b}$ Sebastiano Garroni, ${ }^{b}$ Stamatios Souentie, ${ }^{c}$ Santiago Cuesta-López, ${ }^{* d}$ \\ lakovos Yakoumis, ${ }^{* c}$ and Santiago Aparicio, ${ }^{* a, b}$ \\ ${ }^{a}$ Department of Chemistry, University of Burgos, 09001 Burgos, Spain \\ ${ }^{b}$ International Research Centre in Critical Raw Materials-ICCRAM, University of Burgos, \\ 09001 Burgos, Spain \\ ${ }^{c}$ MONOLITHOS Catalysts \& Recycling Ltd, 11476 Athens, Greece \\ ${ }^{d}$ International Center for Advanced Materials and Raw Materials of Castilla y Leon-ICAMCyL, \\ 24492 Cubillos del Sil (León), Spain
}

Corresponding authors: scuestalopez@gmail.com (S.C.L.), yakoumis@monolithoscatalysts.gr (I. Y.) and sapar@ubu.es (S. A.)

\begin{abstract}
The properties and structure of relevant interfaces involving molten alkali carbonates are studied using molecular dynamics simulations. Lithium carbonate and the $\mathrm{Li} / \mathrm{Na} / \mathrm{K}$ carbonate eutectic mixture are considered. Gas phase composed of pure $\mathrm{CO}_{2}$ or a model flue gas mixture are analysed. Likewise, the adsorption of these gas phases on graphene are studied, showing competitive $\mathrm{CO}_{2}$ and $\mathrm{N}_{2}$ adsorption that develops liquid-like layers and damped oscillation behaviour for density. The interaction of the studied carbonates with graphene is also characterized by development of adsorption layers through strong graphene - carbonate interactions and the development of hexagonal lattice arrangements, especially for lithium carbonate. The development of molten salts - vacuum interfaces is also considered, analysing the ionic rearrangement in the interfacial region. The behaviour of the selected gas phases on top of molten alkyl carbonate is also studied, showing the preferential adsorption of $\mathrm{CO}_{2}$ molecules when flue gases are considered.
\end{abstract}




\section{INTRODUCTION}

Molten salts (MSs) are pivotal for many technologies in the modern industry. ${ }^{1,2}$ Most of the considered MSs applications stand on their unique physicochemical properties ${ }^{3}$ such as thermal stability, ${ }^{4,5,6}$ non-flammability, ${ }^{7}$ low volatility, ${ }^{8}$ ionic and thermal conductivity, ${ }^{9,10}$ moderate viscosity ${ }^{11}$ and solvent capacity. ${ }^{12}$ Likewise, MSs shows low cost, non-toxicity, low environmental impact and large biodegradability, which allow their use in a sustainable framework. ${ }^{13}$ Therefore, applications of MSs in pivotal sectors ${ }^{14}$ such as metallurgy or energy-related operations, mainly as heat storage media or for solar energy applications, ${ }^{15,16,17}$ have been developed these last decades. Molten alkali carbonates (MACs) have attracted great attention into the group of MSs for energy technologies, ${ }^{18}$ especially for fuel cells. ${ }^{19}$ Molten carbonate fuel cells have showed suitable system performance, ${ }^{20}$ robust operations ${ }^{21}$ and a reduced environmental impact. ${ }^{22}$ Likewise, the use of molten carbonates for gas separation operations and in particular for $\mathrm{CO}_{2}$ capture and valorisation, ${ }^{23}$ both using molten carbonate fuel cells ${ }^{24,25}$ and other setups like direct liquid absorption, ${ }^{26,27}$ is among the main applications of these fluids within a sustainable energy framework. MACs have also been used for preparing $\mathrm{CO}_{2}$ separation membranes on several supports. $28,29,30$

The development of MACs - based membranes for industrial applications, especially for carbon capture purposes, could be extended if 2D materials such as graphene were considered as suitable supports for the MACs. Graphene - based membranes for $\mathrm{CO}_{2}$ separation purposes have been considered in the literature both using neat graphene as separation media, i.e. engineering graphene porosity, ${ }^{3132,33,34}$ or with graphene acting as support for $\mathrm{CO}_{2}$ capturing materials, especially for ambient temperature molten salts (i.e. ionic liquids). ${ }^{35,36}$ Although it has been reported that molten carbonates can be used for the direct conversion of $\mathrm{CO}_{2}$ into graphene, ${ }^{37,38}$ the properties of MACs adsorbed on graphene have not been previously studied. Therefore, MACs adsorbed onto graphene surface are considered in this work as a suitable platform for developing $\mathrm{CO}_{2}$ - capturing materials.

A computational approach based on molecular dynamics (MD) simulations was used to infer the main nanoscopic features of the studied systems. The theoretical study will be concentrated on the features of relevant interfacial regions because they are essential for the performance of the whole system. ${ }^{39}$ The considered systems were nanocomposites of MACs adsorbed onto graphene in contact with gas phases formed by pure $\mathrm{CO}_{2}$ and a model 
dried flue gas $\left(\mathrm{CO}_{2}+\mathrm{N}_{2}+\mathrm{O}_{2}\right)$ to consider gas mixtures close to those in fossil fuelled power plants. The studied MACs were pure $\mathrm{Li}_{2} \mathrm{CO}_{3}$ and a ternary eutectic mixture $\left(\mathrm{Li}_{0.87} \mathrm{Na}_{0.63} \mathrm{~K}_{0.50}\right.$ $\mathrm{CO}_{3}$ ) for considering both high and low melting point MACs. ${ }^{39}$ The considered interfaces were: MACs - graphene, MACs - gas (where gas stands for pure $\mathrm{CO}_{2}$ or for the considered flue gas), MACs - vacuum (for comparison purposes with MACs-gas interfaces), and also graphene - gas. Although some theoretical studies on graphene - gas interfaces have been previously reported, ${ }^{40,41}$ the results considered in this work allow to infer the behaviour of complex mixtures on graphene surfaces to compare with their properties for grapheneMACs composites. The results are analysed in terms of properties at interfaces, considering layering, adsorption and the development of solid-like structures for MACs at graphene interfaces. Likewise, dynamic properties of molecules at interfacial regions were studied together with the strength of intermolecular interactions determining the main characteristics of graphene - MACs nanocomposites and the adsorption of the studied gases $\left(\mathrm{CO}_{2}\right)$ at the interfaces.

\section{METHODS}

Molecular dynamics simulations were carried out with MDynaMix v.5.2 molecular modelling package. ${ }^{42}$ Force field parameters for $\mathrm{CO}_{3}{ }^{2-}$ anion and alkali cations $\left(\mathrm{Li}^{+}, \mathrm{Na}^{+}\right.$and $\left.\mathrm{K}^{+}\right)$are reported in Table S1 (Supporting Information) and were obtained from Roest et al. ${ }^{39}$ Graphene was modelled as a rigid entity composed of non-charged carbon atoms interacting through Lennard-Jones potential with interaction parameters previously reported. ${ }^{43}$ Forcefield parameters for $\mathrm{CO}_{2}, \mathrm{~N}_{2}$ and $\mathrm{O}_{2}$ are also reported in Table S1 (Supporting Information). The studied MACs were: i) $\mathrm{Li}_{2} \mathrm{CO}_{3}(m . p .=996.15 \mathrm{~K}$ ) and $i$ ) the eutectic mixture $\mathrm{Li}_{0.87} \mathrm{Na}_{0.63} \mathrm{~K}_{0.50} \mathrm{CO}_{3}$ (i.e. an eutectic mixture composed of $43.5 \% \mathrm{Li}_{2} \mathrm{CO}_{3}+31.5 \% \mathrm{Na}_{2} \mathrm{CO}_{2}+21$ $\% \mathrm{~K}_{2} \mathrm{CO}_{3}$, m.p. $=673 \mathrm{~K}$ ). ${ }^{44}$ The interfaces of interest (gas - graphene, MACs - vacuum, MACs graphene and MACs - gas) were modelled using the systems reported in Table S2 (Supporting Information). Regarding simulations involving graphene, a graphene sheet, in the armchair configuration, containing 1500 carbon atoms with dimensions $62 \times 62 \AA^{2}$ was built and placed in the xy plane, salt and gas layers were placed on top of the sheet initially at $3 \AA$ (Table S2, Supporting Information). The studied gas systems were $i$ ) pure $\mathrm{CO}_{2}$ and ii) a model dry flue gas ( $13.5 \% \mathrm{CO}_{2}+80.9 \% \mathrm{~N}_{2}+5.6 \% \mathrm{O}_{2}$ mixture). Initial simulation boxes were built using the Packmol program. ${ }^{45}$ Simulation were carried out according to a two - steps 
procedure: i) equilibration in the NVT ensemble (assured by the constancy of total potential energy) followed by ii) production runs also in the NVT ensemble (10 ns long). Simulations were carried out at $1023 \mathrm{~K}$ and $673 \mathrm{~K}$ for systems containing $\mathrm{Li}_{2} \mathrm{CO}_{3}$ and $\mathrm{Li}_{0.87} \mathrm{Na}_{0.63} \mathrm{~K}_{0.50} \mathrm{CO}_{3}$, respectively, i.e. assuring that melted salts are considered along the simulations. The temperature along the simulations was controlled by using the Nose-Hoover method. Regarding the possible doubts about the stability of graphene at the temperatures used for simulations, literature studies have showed that graphene films are stable at temperatures up to $973 \mathrm{~K},{ }^{46,47}$ and even in air no remarkable degradation is inferred up to $923 \mathrm{~K}^{47}$ Coulombic interactions were handled with Ewald method, with $15 \AA$ cut-off radius. The equations of motion were solved with the Tuckerman-Berne double time step algorithm ${ }^{48}$ (1 and $0.1 \mathrm{fs}$ for long and short time steps). Cross Lennard-Jones terms were calculated according to the Lorentz-Berthelot mixing rules. A cutoff of $15 \AA$ was considered for LennardJones interactions.

\section{RESULTS AND DISCUSSION}

Gas - Graphene Interface. The first interface analysed in this work is obtained from the adsorption of $\mathrm{CO}_{2}$ on graphene. Adsorption from a pure $\mathrm{CO}_{2}$ gas and from the studied flue gas - like mixture were considered $\left(\mathrm{CO}_{2}+\mathrm{N}_{2}+\mathrm{O}_{2}\right)$. Lee et al. ${ }^{40}$ showed through Density Functional Theory (DFT) calculations that $\mathrm{CO}_{2}$ molecules are physisorbed onto graphene surface with 8.79 and $13.81 \mathrm{~kJ} \mathrm{~mol}^{-1}$ interaction energies, for perpendicular and parallel arrangements, respectively, which are lower than the values reported by Takeuchi et al. ${ }^{41}$ for parallel arrangement using a different DFT (functional) approach $\left(26.2 \mathrm{~kJ} \mathrm{~mol}^{-1}\right)$. These theoretical results show preferential arrangement of $\mathrm{CO}_{2}$ molecules on graphene surface with gas molecules placed at $3.2 \AA$. Takeuchi et al. ${ }^{41}$ also showed and experimental coverage of $\mathrm{CO}_{2}$ on graphene of $\theta=0.10$. Therefore, the structure of the adsorbed $\mathrm{CO}_{2}$ on graphene was firstly analysed through the number density profiles in perpendicular direction to the graphene surface, Figure 1. Results in Figure 1a show that adsorption from pure $\mathrm{CO}_{2}$ gas phase leads to a highly structured region above the graphene surface. This region is characterized by three layers of $\mathrm{CO}_{2}$ molecules adopting a parallel arrangement about graphene (peaks [1], [3] and [5] in number density profiles of Figure 1a), the maxima of peak [1] (3.2 $\AA$ agrees with DFT results reported by Takeuchi et al. ${ }^{41}$ ). These three layers are 
separated by two less dense ones (peaks [2] and [4] in Figure 1a) in which $\mathrm{CO}_{2}$ molecules are adopting a perpendicular arrangement to graphene. Therefore, a layering, alternating parallel-perpendicular arrangement of $\mathrm{CO}_{2}$ molecules is obtained when $\mathrm{CO}_{2}$ molecules are adsorbed from a pure $\mathrm{CO}_{2}$ gas phase (bottom panel of Figure 1a). The planar arrangement of $\mathrm{CO}_{2}$ molecules in the first adsorbed layer is confirmed in Figure S2 (Supporting Information). In the case of gas adsorption from flue gas mixture (Figure 1b), the reported results show different behaviour in comparison with pure $\mathrm{CO}_{2}$, mainly because of the presence of $\mathrm{N}_{2}$ molecules (and in minor extension of $\mathrm{O}_{2}$ molecules) which are coadsorbed on the graphene results. Ohba et al. ${ }^{49}$ reported through a Monte - Carlo theoretical study that $\mathrm{N}_{2}$ molecules are adsorbed on graphene, developing a first adsorbed layer at $3.4 \AA$ with $8.7 \mathrm{~kJ} \mathrm{~mol}^{-1}$ interaction energy. Hence, although graphene- $\mathrm{N}_{2}$ interaction energies are lower than graphene $-\mathrm{CO}_{2}$ ones, it may be expected that both molecules compete for adsorption site onto graphene surface. This is confirmed by the number density profiles reported in Figure 1b. A first adsorbed layer on graphene is formed by $\mathrm{CO}_{2}$ and $\mathrm{N}_{2}$ molecules, with slightly larger concentration for $\mathrm{CO}_{2}$ molecules despite the larger $\mathrm{N}_{2}$ concentration in bulk flue gas phase. $\mathrm{N}_{2}$ molecules are placed slightly closer to the graphene surface in comparison with $\mathrm{CO}_{2}$ molecules ( 3.3 and $3.5 \AA$ for the first maxima reported in Figure $1 \mathrm{~b}$ ) and both $\mathrm{N}_{2}$ and $\mathrm{CO}_{2}$ molecules adopt a parallel configuration regarding the graphene surface for the first adsorbed layer. This first adsorbed layer if followed by a region with a low concentration of $\mathrm{N}_{2}$ molecules adopting a perpendicular arrangement to the surface (the first shoulder after peak [1] for $\mathrm{N}_{2}$ in Figure $1 \mathrm{~b}$ ) but $\mathrm{CO}_{2}$ molecules are absent in this region in contrast with the behaviour reported for adsorption from pure $\mathrm{CO}_{2}$ (Figure 1a). The structure for outer adsorption layers is characterized by a prevailing presence of $\mathrm{N}_{2}$ molecules, peaks [3] and [5] in Figure $1 \mathrm{~b}$ being remarkably larger than those for $\mathrm{CO}_{2}$. Therefore, $\mathrm{CO}_{2}$ molecules tend to concentrate in the first adsorbed layer, whereas $\mathrm{N}_{2}$ molecules are present in all the adsorbed layers, with $\mathrm{O}_{2}$ molecules being minor components in the first three layers. The structure of this first adsorbed layer is highly heterogeneous with $\mathrm{CO}_{2}$ molecules (also adopting a planar configuration) and $\mathrm{N}_{2}$ molecules placed in different regions on top of graphene surface (Figure S2, Supporting Information). The adsorption from the flue gas mixture leads to a remarkably larger layering when compared with adsorption from pure $\mathrm{CO}_{2}$, bottom panels of Figures $1 a$ and $1 b$, with this layering extending up to $30 \AA$ from graphene surface, Figure $2 a$. This largely layered adsorption structure rising from adsorption layers formed mainly by $\mathrm{N}_{2}$ 
molecules, except for the first layer in direct contact with graphene, shows up to nine layers as reported by the behaviour of number density profiles reported in Figure 2a showing a damped oscillation behaviour (with a periodicity of $5 \AA$ ). This oscillation behaviour of density profiles on graphene has been previously reported for other types of molecules such as ionic liquids, ${ }^{50}$ with the same periodicity but with larger oscillation period and minor extension of the oscillations (i.e. larger damping) usually with layers being limited to $20 \AA$ from the graphene surface. The positions and the values of the maxima for $\mathrm{N}_{2}$ density profiles are reported in Figure $2 b$ showing a non-linear behaviour corresponding to an attenuation of the layering upon increasing the distance with the graphene surface; nevertheless, it should be remarked that although the layering decreases on going to high temperatures, up to four well defined layers are obtained at $1023 \mathrm{~K}$.

The development of the gas adsorbed layers on graphene is analysed through the time evolution of graphene-gas interaction energies reported in Figure 3. These results show that in the case of adsorption from pure $\mathrm{CO}_{2}$, the adsorbed layers are developed in 3 ns (determined through the constancy of interaction energy) with negligible differences for the two considered temperatures, whereas in the case of adsorption from the flue gas mixture it takes up to $7 \mathrm{~ns}$ to develop the complex layering showed in Figure $2 \mathrm{~b}$. This slower kinetics for the adsorption from flue gas mixture stand on the spatial reorganization of the first adsorbed layer for fitting both $\mathrm{CO}_{2}$ and $\mathrm{N}_{2}$ molecules, and on the other side for the large number of layers obtained beyond the first adsorbed layer. The interaction energies are twofold for $\mathrm{CO}_{2}$ than for $\mathrm{N}_{2}$, in agreement with DFT literature results, ${ }^{40,41}$ in spite of the first adsorbed layer (in direct contact with graphene) showing almost equivalent concentration of both types of molecules, Figure $2 \mathrm{~b}$. Likewise, it should be remarked that although $\mathrm{O}_{2}$ molecules are present in the first three adsorbed layers, its concentration is low and thus $\mathrm{O}_{2^{-}}$ graphene interaction energies are also weak. Moreover, strong $\mathrm{N}_{2} / \mathrm{CO}_{2}$-graphene interactions are produced even for high temperature (1023 K), and thus, confirming the affinity of graphene for both molecules.

The structuring of considered gases suffers changes upon adsorption on graphene as shown by the radial distribution functions (RDFs) reported in Figure 4 . In the case of pure $\mathrm{CO}_{2}$, Figure $4 \mathrm{a}, \mathrm{CO}_{2}$ molecules in the first adsorbed layer show a more ordered structure in comparison with bulk $\mathrm{CO}_{2}$ in gas phase, as shown by the increase in the intensities of the reported radial distribution functions, leading to a liquid-like structure for the layer in direct 
contact with graphene, in agreement with previous literature results for adsorption on graphite surface. ${ }^{51}$ Nevertheless, the position of the maxima for the peaks in radial distribution functions (at 4.1 and $7.1 \AA$ ) remains constant upon adsorption, and thus, the mechanism of interaction between $\mathrm{CO}_{2}$ molecules is the same both in bulk gas phase and in the first adsorbed layer, where the presence of graphene layer increases density because of strong $\mathrm{CO}_{2}$ - graphene interactions, and thus, also increases $\mathrm{CO}_{2}-\mathrm{CO}_{2}$ interactions. Regarding the adsorption from the flue gas mixture, results in Figure $4 \mathrm{~b}$ show that $\mathrm{CO}_{2}-\mathrm{CO}_{2}$ interactions in the first adsorbed layer are very like those in the bulk gas mixture for the first solvation shell, but interactions beyond this shell are disrupted. Interactions of $\mathrm{N}_{2}-\mathrm{N}_{2}$ and $\mathrm{O}_{2}-\mathrm{O}_{2}$ types are also disrupted in the first adsorbed layer, whereas heteroassociations (Figure 4c) suffer remarkable changes. $\mathrm{CO}_{2}-\mathrm{N}_{2}$ interactions are weakened upon adsorption whereas $\mathrm{N}_{2}-\mathrm{O}_{2}$ are reinforced. Therefore, the structure of the first adsorbed layer from flue gas is very different to that in bulk flue gas because the preferential interactions between the gases and graphene reported in Figures $1 b$ and $2 b$ produces a structural rearrangement of molecules on the graphene surface.

The large interaction energies reported in Figure 3 for gas - graphene systems should lead to a decrease in molecular mobility for molecules placed in the first adsorbed layer in comparison with bulk gas phases. This effect is quantified in Figure 5 reporting the ratio of self-diffusion coefficients in the plane parallel to graphene surface $\left(D_{x y}\right)$ for molecules in the first adsorbed layer in comparison with bulk phase. The reported results show that for the lowest studied temperature the molecular mobility in the first adsorbed layer is remarkably lower than in the bulk gas phases, in agreement with the liquid - like behaviour inferred from results in Figures 1 and 4. The decrease in mobility is larger for the case of adsorption from flue gas mixture than for pure $\mathrm{CO}_{2}$, which shows that in the case of flue gases the interactions between gas molecules in a liquid-like arrangement reported in Figures $4 \mathrm{~b}$ and $4 \mathrm{c}$ also contributes to the decrease in mobility adding an additional contribution to the gas graphene interactions. Likewise, in the case of flue gases the decrease of molecular mobility upon adsorption is equivalent for the three types of molecules $\left(\mathrm{CO}_{2}, \mathrm{~N}_{2}\right.$ and $\left.\mathrm{O}_{2}\right)$ confirming the development of heteroassociation between these molecules as reported in Figure 4c. The decrease in molecular mobility is very sensitive to the considered temperature because results in Figure 5 show $D_{x y}$ for molecules in the interface close to those in bulk phase. This can be justified considering the decrease in the strength of gas - graphene interactions, 
especially for $\mathrm{CO}_{2}$-graphene ones (Figure 3), leading to a decrease of layering and densification upon adsorption (Figure 2) but also by the weakening of gas-gas interactions, all these factors decreasing the liquid-like behaviour of the adsorbed layer with increasing temperature.

MACs - Vacuum Interface. The main objective of this work is to analyse the interfaces involving the considered MACs, and thus, in this section the properties of the interface between MACs and a vacuum layer is studied to infer the structural rearrangements of ions because of the presence of this interface. Number density profiles near the Gibbs dividing surface (GDS) are reported in Figure 6a for the case of $\mathrm{Li}_{2} \mathrm{CO}_{3}$ showing a rearrangement of ions at the interface. A weak peak for $\mathrm{Li}^{+}$is inferred below the GDS at $2 \AA$ whereas another one is obtained for carbon atoms in carbonate ion at $0.5 \AA$ below the GDS, therefore an enrichment of the region just below the GDS for carbonate ions is produced in comparison with the bulk liquid region. Another remarkable feature inferred from Figure 6a stands on the position of the maximum for carbon atoms being closer to the GDS than the ones for oxygen atoms in carbonate anion that are placed in inner regions, i.e. the planarity of carbonate ions is modified by the presence of the vacuum interface with oxygen atoms being placed closer to lithium cations and carbon atoms close to the interface. The disruptive effect because of the vacuum interface is also inferred from the oscillating density profiles reported in Figure 6a, especially remarkable for carbon atoms in carbonate. In the case of $\mathrm{Li}_{0.87} \mathrm{Na}_{0.63} \mathrm{~K}_{0.50} \mathrm{CO}_{3}$ eutectic mixture, Figure $6 \mathrm{~b}$, the presence of three types of alkali cations leads to a complicated picture of the structure at the vacuum interface, very different to that in $\mathrm{Li}_{2} \mathrm{CO}_{3}$. $\mathrm{Li}, \mathrm{Na}$ and $\mathrm{K}$ cations are present in regions both above and below the GDS but whereas Li prevails in the region below GDS, the $\mathrm{K}$ cation prevails in the region above the GDS, showing a heterogeneous distribution of cations in the interface region. Regarding the distribution of carbonate anions, the presence of three types of cations induces a larger oscillating behavior of number density profiles (four maxima for carbon profiles are inferred in the case of $\mathrm{Li}_{0.87} \mathrm{Na}_{0.63} \mathrm{~K}_{0.50} \mathrm{CO}_{3}$ in contrast with only two for $\mathrm{Li}_{2} \mathrm{CO}_{3}$ ), which shows the formation of larger layering in the case of the eutectic MACs.

The layering structure near vacuum interface is confirmed by the total charge density profiles reported in Figure $6 \mathrm{c}$ for the region around GDS. These alternating regions of positive and negative charges indicate carbonate anions and alkali cations occupying 
different regions below the GDS, whereas the region above GDS does not show a neat charge.

MACs - Graphene Interface. The adsorption of MACs at the graphene interface is analysed in this section. Densification and layering of molten salts on graphene have been previously reported, especially for ionic liquids, ${ }^{52,53,54}$ whereas it has also been reported for MACs over other surfaces such as metals. ${ }^{39}$ The adsorption of $\mathrm{Li}_{2} \mathrm{CO}_{3}$ on graphene leading to densification and layering with an oscillatory damped behaviour for number density profiles is confirmed in this work (Figure 7a). The region $20 \AA$ above graphene is characterized by five adsorption layers for lithium and carbonate cations. Carbonate cations are placed closer to graphene surface for the first adsorbed layer as the maxima at 3.38 and $4.31 \AA$ show. Likewise, carbon atoms in carbonate are roughly $0.5 \AA$ closer to the surface than oxygen atoms, which show disruption of planar structure of carbonate cations, as was also reported for the vacuum interface. Regarding adsorption layers beyond the first one, results in Figure 7a show that lithium cation and carbonate anions lead to alternating density profiles, i.e. the maxima of cations is place for the minima of anions, therefore pointing to alternating cationanion layers separated by 1-2 $\AA$. In the case of $\mathrm{Li}_{0.87} \mathrm{Na}_{0.63} \mathrm{~K}_{0.50} \mathrm{CO}_{3}$ eutectic mixture, densification and layering is also produced but in a minor extension as the lower values for the corresponding density peaks show (Figures 7a and 7b). In the eutectic mixture, the first high density peak for lithium almost vanish because sodium and specially potassium cations are placed in regions closer to graphene surface. Likewise, oscillations for number density profiles in the case of $\mathrm{Li}_{0.87} \mathrm{Na}_{0.63} \mathrm{~K}_{0.50} \mathrm{CO}_{3}$ eutectic mixture extend to shorter distances in comparison with $\mathrm{Li}_{2} \mathrm{CO}_{3}$, i.e. larger damping constant leading to a decrease of layering. This is confirmed by the large oscillations inferred for charge density profiles obtained for $\mathrm{Li}_{2} \mathrm{CO}_{3}$, which are damped on going to the eutectic mixture, Figure $7 \mathrm{c}$.

The large differences in the structures of adsorbed layers for $\mathrm{Li}_{2} \mathrm{CO}_{3}$ and $\mathrm{Li}_{0.87} \mathrm{Na}_{0.63} \mathrm{~K}_{0.50} \mathrm{CO}_{3}$ eutectic mixtures are confirmed by the arrangements reported in Figure 8. In the case of $\mathrm{Li}_{2} \mathrm{CO}_{3}$, a highly ordered structure for the first adsorbed layer is inferred, a pattern is extended above the graphene surface with lithium cations adopting a hexagonal distribution with carbonate cations placed in the center of these hexagons, Figure 8a. Hexagonal distributions of molten salts have been previously reported in the literature; Kislenko et al. $^{50}$ have reported analogous hexagonal arrangements for alkylimidazolium- 
based ionic liquids. The lattice spacing for the hexagonal arrangement of ions reported in Figure $8 \mathrm{a}$ is two-times larger than the one of graphene whereas Kislenko et al. ${ }^{50}$ have reported lattice for the studied ionic liquid four times larger, which can be justified considering the smaller size of ions involved in $\mathrm{Li}_{2} \mathrm{CO}_{3}$ adsorption in comparison with bulky alkylimidazolium cations. Nevertheless, it seems that for simple molten salts they adopt a hexagonal distribution resembling that of the graphene substrate, with lattice constants depending on the size of involved ions. These hexagonal arrangements lead to an efficient ion-graphene interaction maximizing the adsorption of the salts. In the case of $\mathrm{Li}_{0.87} \mathrm{Na}_{0.63} \mathrm{~K}_{0.50} \mathrm{CO}_{3}$ eutectic, the presence of three different types of cations with very different sizes (Table S1, Supporting Information) introduce a disruption in the structuring of the first adsorbed layer, and although a certain ordering is inferred hexagonal lattices are not formed, Figure $8 \mathrm{~b}$. Nevertheless, in the case of the studied eutectic mixture, the distribution of ions in the first adsorbed layer is characterized by isolated carbonate cations surrounded by alkali cations, with shells around the carbonate composed by mixtures of the three considered types of cations, Figure $8 \mathrm{~b}$.

The structure of the first adsorbed layer on graphene in comparison with bulk liquid MACs is analysed through RDFs reported in Figure 9. For $\mathrm{Li}_{2} \mathrm{CO}_{3}$ adsorption, RDFs for carboncarbon interactions shows a first peak wider for carbonate ion in the adsorbed layer than in the bulk fluid, Figure 9a, because of the molecular arrangement (hexagonal lattice) reported in Figure 8a. In the case of the interactions between lithium cation and carbonate anion and for the lithium-lithium ones, RDFs are very similar as those in the bulk region because the hexagonal lattice arrangement allows a close contact between lithium and carbonate ions, Figures $9 \mathrm{a}$ and $9 \mathrm{~b}$. In the case of the eutectic mixture, RDFs corresponding to carbonate carbonate interactions, Figure 9c, shows a widening of the first solvation peak, which is again justified by the dispersion of carbonate anions on top of the graphene surface. Regarding the distribution of alkali cations, the bulk liquid phase is characterized by solvation shells with lithium cation placed in inner regions, followed by sodium and potassium (Figure 9c) because of the cations size which allow a fitting of the smaller cation (lithium) in regions closer to the carbonate anion. This pattern is maintained with minor changes for the eutectic in the first solvation layer (Figure 9c). Regarding the patterns for cation-cation interactions in the eutectic mixture, the complex patterns reported in Figure $9 \mathrm{~d}$ for the bulk liquid phase are maintained for the cations in the first adsorbed layer, with a minor widening of RDFs 
peak corresponding to the cation distribution on top of the graphene surface. The reported RDFs allow the calculation of ions in the solvation spheres around another type of ion as reported in Figure 10. The reported results reveal a decrease in the number of molecules around another one for all the considered ion-ion pairs and MACs on going from the bulk liquid phase to the first adsorbed layer. However, the relative composition of the solvation shells, i.e. the ratio between the considered ions in each shell, is maintained on going to the graphene surface, which can be justified from the differences of ionic arrangement in a 3D and $2 \mathrm{D}$ regions. Therefore, the mechanism of ion-ion interactions in bulk liquid phase both for $\mathrm{Li}_{2} \mathrm{CO}_{3}$ and for the eutectic mixture is maintained upon adsorption on graphene, even though the development of the hexagonal lattice arrangements reported in Figure 8.

The kinetics of the development of adsorption layers for both MACs on graphene is analyzed through the ion-graphene interaction energies reported in Figure 11. Adsorbed layers are developed in just $1 \mathrm{~ns}$ both for $\mathrm{Li}_{2} \mathrm{CO}_{3}$ and for the eutectic mixture, which shows that the structure of adsorbed layers is developed very quickly, which considering the remarkable ionic arrangements produced upon adsorption (the hexagonal lattice for $\mathrm{Li}_{2} \mathrm{CO}_{3}$ ) is highly remarkable. This quick adsorption is guided by the large affinity of carbonate anion for graphene surface, this effect is quantified by the ion-graphene interaction energies reported in Figure 11 which are two orders of magnitude larger for the carbonate anion than for the considered alkali cations in both MACs. Likewise, carbonate - graphene interactions are less effective in the case of the studied eutectic mixture when compared with $\mathrm{Li}_{2} \mathrm{CO}_{3}$, which agrees with the weaker densification upon adsorption reported in Figure 7 for the eutectic mixture. Regarding the cation-graphene interactions, although being weaker than carbonate-graphene ones, they are also remarkable, it should be remarked that density profiles reported in Figure 7 showed that alkali cations are placed at larger distances of graphene than carbonate, which also contributes to weaker interactions. In the case of lithium-graphene interactions, they are less effective on going from $\mathrm{Li}_{2} \mathrm{CO}_{3}$ to the eutectic mixture, Figure 11a, because of the dilution effect by the presence of other types of larger cations. Likewise, lithium-graphene and sodium-graphene interactions are larger than potassium-graphene ones. Therefore, from the viewpoint of ion-graphene interactions, the adsorption is guided by carbonate-graphene interactions, maximizing the number of contacts between the anion and the underlying carbon atoms of graphene with cation placed in lattices allowing effective ion-graphene interactions. The presence of cations larger 
than lithium disrupts the adsorbed network, decreasing the extension of carbonate graphene interactions and leading to a less effective adsorption from the viewpoint of interaction energy and densification upon adsorption.

MACs - Graphene - Gas Interface. As a final stage of this study we report the behaviour of MACs at gas interface, when the MAC is supported on graphene, where the gas phase is pure $\mathrm{CO}_{2}$ or the flue gas mixture, which are of relevance considering graphene-MAC nanocomposites for $\mathrm{CO}_{2}$ capturing purposes using a physical adsorption mechanism. The number density profiles at MACs-gas interface are reported both for pure $\mathrm{Li}_{2} \mathrm{CO}_{3}$ and for the eutectic mixture for both gas systems in Figure 12. In the case of a gas phase composed only by $\mathrm{CO}_{2}$ molecules, Figure 12a, number density profiles do not show densification on top of the MACs liquid layer, with similar density profiles for both types of MACs close to those in the gas layer. Therefore, $\mathrm{CO}_{2}$ molecules are not remarkably adsorbed at the MACs interface in contact with pure $\mathrm{CO}_{2}$. The behavior of the adsorption from the flue gas mixture is totally different, Figure $12 \mathrm{~b}, \mathrm{CO}_{2}$ densification is clearly inferred on top of the MACs liquid layer leading to a liquid - like $\mathrm{CO}_{2}$ adsorbed layer on $\mathrm{Li}_{2} \mathrm{CO}_{3}$ and the eutectic mixture. The structure of flue gas on top of the studied MACs is characterized by a dense adsorbed layer of $\mathrm{CO}_{2}$ molecules in direct contact with the MACs followed by gas-like layer composed by $\mathrm{N}_{2}$ molecules, no adsorption of $\mathrm{N}_{2}$ molecules is inferred, Figure $12 \mathrm{~b}$. This structuring is confirmed by the isosurfaces reported in Figure 13, in which the preferential adsorption of $\mathrm{CO}_{2}$ from flue gases is in contrast with the behavior of pure $\mathrm{CO}_{2}$ gas phase. In the case of MACs-pure $\mathrm{CO}_{2}$ interfaces, a remarkable feature inferred is the curved interface in contrast with the planarity of MACs-flue gas interfaces, Figures $13 \mathrm{~b}$ and $13 \mathrm{~d}$. Molecules adsorbed on MACs-gas interfaces adopt a parallel orientation regarding MACs surface, Figure 14. This parallel orientation of $\mathrm{CO}_{2}$ molecules is adopted to maximize van der Waals interactions, which are favorable for cation- $\mathrm{CO}_{2}$ pairs, Figure 15 . The main differences between the interaction energies in the cases of interactions with pure $\mathrm{CO}_{2}$ or with flue gas mixture stand on i) larger $\mathrm{CO}_{2}-\mathrm{Li}$ interactions (and decrease of $\mathrm{CO}_{2}-\mathrm{Na}$ and $\mathrm{CO}_{2}-\mathrm{K}$ ) and ii) and weaker $\mathrm{CO}_{2}-$ carbonate cation positive energies on going to flue gas mixture. The only gas adsorbed on the MACs from flue gas mixture interface is $\mathrm{CO}_{2}$ as the almost negligible interaction energies for $\mathrm{N}_{2}$ and $\mathrm{O}_{2}$ reported in Figure S3 (Supporting Information) show. 
The structure of the liquid-like adsorbed layer and the interacting pairs is analyzed through relevant RDFs reported in Figure 16. A comparison of the reported RDFs for the case of pure $\mathrm{CO}_{2}$ gas phase (no adsorption), Figure 16a, and for the case of flue gas mixture phase (adsorption) shows that ion- $\mathrm{CO}_{2}$ interactions are only developed in the case of flue gas mixture. In the case of the eutectic mixture the lithium cations are closer to $\mathrm{CO}_{2}$ molecules, followed by sodium and potassium ones, which should be placed in inner regions of the interfacial regions, in contrast with the behavior of MACs-vacuum interfaces reported in Figure 6, i.e. the interface is rearranged by the presence of the flue gas phase to accommodate (adsorb) $\mathrm{CO}_{2}$ molecules.

\section{CONCLUSIONS}

The behaviour of molten alkali carbonates at graphene, vacuum and gas $\left(\mathrm{CO}_{2}\right.$ and flue gas) interfaces is studied using molecular dynamics simulations. Likewise, the adsorption of $\mathrm{CO}_{2}$ at graphene interface is also considered. $\mathrm{CO}_{2}$ molecules are strongly adsorbed on graphene surface, adopting parallel arrangements regarding the surface, leading to layering and liquidlike densification both from pure $\mathrm{CO}_{2}$ and flue gas mixtures. In the case of flue gas, $\mathrm{N}_{2}$ molecules are also adsorbed leading to stratification on graphene with up to nine adsorbed layers following an oscillating damping behaviour for number density profiles even for high temperature. The interface of molten alkali carbonates with vacuum is characterized by layering with carbonate anions and alkali occupying different regions above and below the Gibbs dividing surface. Molten alkali carbonates are adsorbed on graphene, both for pure $\mathrm{Li}_{2} \mathrm{CO}_{3}$ and for the studied eutectic mixture, with carbonate anions being placed closer to graphene surface, adopting a slightly disrupted parallel configuration, and alkali cations in slightly outer regions, i.e. leading to charged regions above graphene surface. In the case of pure $\mathrm{Li}_{2} \mathrm{CO}_{3}$ adsorbed ions adopt a hexagonal lattice distribution, with lattice constant two times larger than the one for graphene, which is disrupted when the eutectic mixture is adsorbed. The adsorption of molten alkali carbonates is guided by the strong carbonate graphene interactions in comparison with the weaker alkali cations - graphene interactions. Finally, the structure of molten alkali carbonates in contact with gas phases is also studied showing that $\mathrm{CO}_{2}$ molecules are not adsorbed when the carbonates are in contact with a pure $\mathrm{CO}_{2}$ gas phase in contrast with the large adsorption when flue gas mixture is present. The adsorption of $\mathrm{CO}_{2}$ molecules is not accompanied by $\mathrm{N}_{2}$ molecules, which are weakly 
interacting with the molten alkali carbonate ions, thus showing high selectivity of the studied molten salts for the $\mathrm{CO}_{2} / \mathrm{N}_{2}$ pair, which is of relevance for $\mathrm{CO}_{2}$ capturing from flue gas mixtures.

\section{ACKNOWLEDGEMENT}

This work was made possible by European's Union H2020-MSCA-RISE-2016-CO2MPRISE734873 project. We also acknowledge SCAYLE (Supercomputación Castilla y León) for providing supercomputing facilities. The statements made herein are solely the responsibility of the authors.

\section{ASSOCIATED CONTENT}

\section{Supporting Information}

Table S1 (force field parameterization); Table S2 (systems used for molecular dynamics simulations); Figure S1 (temperature effect on number density profiles for graphene + gas interfaces); Figure S2 (distribution of gas molecules in the first adsorbed layer for graphene + gas interfaces); Figure S3 (time evolution of interaction energies for gas + salt interfaces). 


\section{Figure Captions.}

Figure 1. Number density profiles for the centers-of-mass of gas molecules in perpendicular direction to graphene for (a) graphene $+\mathrm{CO}_{2}$ and (b) graphene + flue gas interfaces. Graphene is placed at $d=0$. All values at $673 \mathrm{~K}$. The numbers inside each panel show the $d(\AA)$ corresponding to the maxima.

Figure 2. (a) Extended plot of number density profiles the centers-of-mass of gas molecules in perpendicular direction to graphene for graphene + flue gas interfaces at two temperatures, and (b) ratio between the position of the maxima, $d_{\max }$ and the corresponding density, $\rho_{\max }$. The numbers inside panel (a) show the $d(\AA)$ corresponding to the maxima.

Figure 3. Simulation time evolution of interaction energy between gas molecules and graphene for (a) graphene $+\mathrm{CO}_{2}$ and $(\mathrm{b})$ graphene + flue gas interfaces

Figure 4. Center-of-mass radial distribution functions, $g(r)$, for the reported molecular pairs for (a) graphene + $\mathrm{CO}_{2}$ and $(b, c)$ graphene + flue gas interfaces. First adsorbed layer defined according to density profiles reported in Figure $1(d<5 \AA$ ) . All values at $673 \mathrm{~K}$.

Figure 5. Ratios between the self-diffusion coefficients in the plane parallel to graphene surface, $D_{x y}$, for the reported molecules in the $1^{\text {st }}$ adsorbed layer and in the pseudobulk regions for graphene $+\mathrm{CO}_{2}$ and graphene + flue gas interfaces. $D_{x y}$ values calculated from mean square displacements and Einstein's equation.

Figure 6. $(a, b)$ Number density, $\rho$, and (c) charge density profiles, $\rho_{e}$, in perpendicular direction to MAC-vacuum interface for the reported MACs. $d_{\mathrm{GDS}}$ stands for the position (z-axis) of the Gibbs dividing surface. Values for $\mathrm{Li}_{2} \mathrm{CO}_{3}$ and $\mathrm{Li}_{0.87} \mathrm{Na}_{0.63} \mathrm{~K}_{0.50} \mathrm{CO}_{3}$ (eutectic mixture) are for 1023 and $673 \mathrm{~K}$, respectively.

Figure 7. $(a, b)$ Number density, $\rho$, and (c) charge density profiles, $\rho_{e}$, in perpendicular direction to graphene surface for the reported MACs. Graphene is placed at $d=0$. Values for $\mathrm{Li}_{2} \mathrm{CO}_{3}$ and $\mathrm{Li}_{0.87} \mathrm{Na}_{0.63} \mathrm{~K}_{0.50} \mathrm{CO}_{3}$ (eutectic mixture) are for 1023 and $673 \mathrm{~K}$, respectively. 
Figure 8. Snapshots of ions on top of graphene for the reported MAC-graphene interfaces, ions with $d<5 \AA$ (where $d$ stands for distance to graphene, i.e. first adsorbed layer) are included. Values for $\mathrm{Li}_{2} \mathrm{CO}_{3}$ and $\mathrm{Li}_{0.87} \mathrm{Na}_{0.63} \mathrm{~K}_{0.50} \mathrm{CO}_{3}$ (eutectic mixture) are for 1023 and $673 \mathrm{~K}$, respectively. White lines at the bottom of panel (a) are reported to show the hexagonal pattern of adsorbed ions around carbonate anions.

Figure 9. Center-of-mass radial distribution functions, $g(r)$, for the reported pairs for graphene - MAC interfaces. All values at $673 \mathrm{~K}$. Values for $\mathrm{Li}_{2} \mathrm{CO}_{3}$ and $\mathrm{Li}_{0.87} \mathrm{Na}_{0.63} \mathrm{~K}_{0.50} \mathrm{CO}_{3}$ (eutectic mixture) are for 1023 and 673 K, respectively. First adsorbed layer defined according to density profiles reported in Figure 7 ( $d<5 \AA$ ). Values for pseudobulk regions (top of each panel) are shifted to improve visibility.

Figure 10. Number of molecules, $N$, is the first solvation sphere (defined according to results in Figure 9 ) for the reported pairs for graphene - MAC interfaces. Values for $\mathrm{Li}_{2} \mathrm{CO}_{3}$ and $\mathrm{Li}_{0.87} \mathrm{Na}_{0.63} \mathrm{~K}_{0.50} \mathrm{CO}_{3}$ (eutectic mixture) are for 1023 and $673 \mathrm{~K}$, respectively.

Figure 11. Simulation time evolution of interaction energy between reported molecules and graphene for graphene + MAC interfaces. Values for $\mathrm{Li}_{2} \mathrm{CO}_{3}$ and $\mathrm{Li}_{0.87} \mathrm{Na}_{0.63} \mathrm{~K}_{0.50} \mathrm{CO}_{3}$ (eutectic mixture) are for 1023 and $673 \mathrm{~K}$, respectively.

Figure 12. Snapshots and number density profiles, $\rho$, in perpendicular direction to MAC-gas interfaces for the reported MACs. $d_{G D S}$ stands for the position (z-axis) of the Gibbs dividing surface. Values for $\mathrm{Li}_{2} \mathrm{CO}_{3}$ and $\mathrm{Li}_{0.87} \mathrm{Na}_{0.63} \mathrm{~K}_{0.50} \mathrm{CO}_{3}$ (eutectic mixture) are for 1023 and $673 \mathrm{~K}$, respectively. Simulated systems consist on a graphene $+\mathrm{MAC}+$ gas. Results in panel $\mathrm{a}$ and panel b correspond to interfaces with pure $\mathrm{CO}_{2}$ and with $\mathrm{CO}_{2}+\mathrm{N}_{2}+\mathrm{O}_{2}$ gas mixture, respectively. The snapshots show in small dots the MAC and in large balls the gas molecules.

Figure 13. Number density isosurfaces for the reported systems. Panels a and c show distribution on top of $\mathrm{Li}_{2} \mathrm{CO}_{3}$ - gas interface and panels $b$ and $d$ on plane perpendicular to the interface. Left side of panels $b$ and $d$ show the MAC and right sides the gas.

Figure 14. Probability distribution plots for the angle formed between $\mathrm{CO}_{2}$ molecules and a vector perpendicular to the MAC - gas interfaces. Only molecules in the first adsorbed layer are considered.

Figure 15. Simulation time evolution of interaction energy between reported molecules for MAC + gas interfaces. Values for $\mathrm{Li}_{2} \mathrm{CO}_{3}$ and $\mathrm{Li}_{0.87} \mathrm{Na}_{0.63} \mathrm{~K}_{0.50} \mathrm{CO}_{3}$ (eutectic mixture) are for 1023 and $673 \mathrm{~K}$, respectively. Simulated systems consist on a graphene + MAC + gas. 
Figure 16. Center-of-mass radial distribution functions, $g(r)$, for the reported pairs for MAC + gas interfaces. Values for $\mathrm{Li}_{2} \mathrm{CO}_{3}$ and $\mathrm{Li}_{0.87} \mathrm{Na}_{0.63} \mathrm{~K}_{0.50} \mathrm{CO}_{3}$ (eutectic mixture) are for 1023 and $673 \mathrm{~K}$, respectively. Simulated systems consist on a graphene $+\mathrm{MAC}+$ gas.
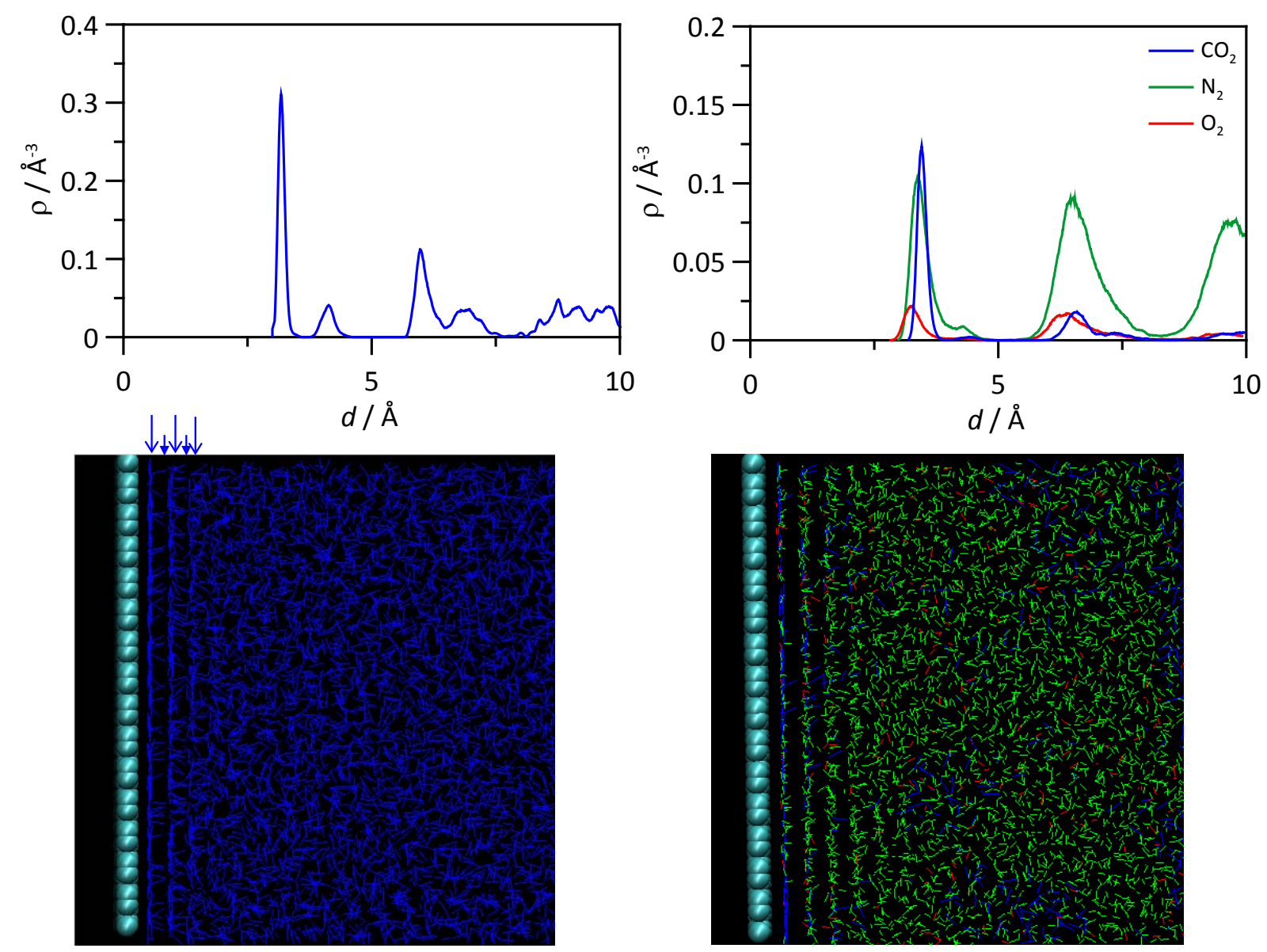

Figure 1. 

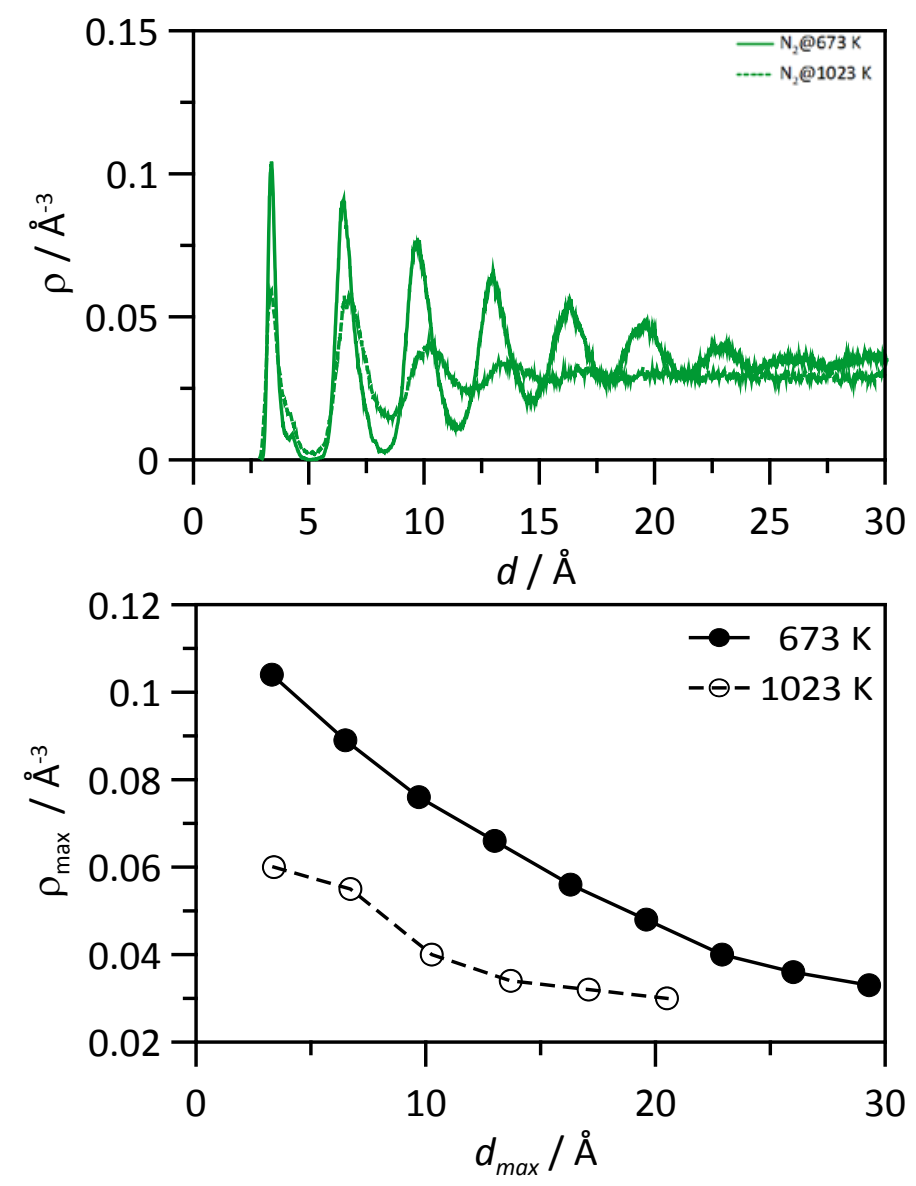

Figure 2. 

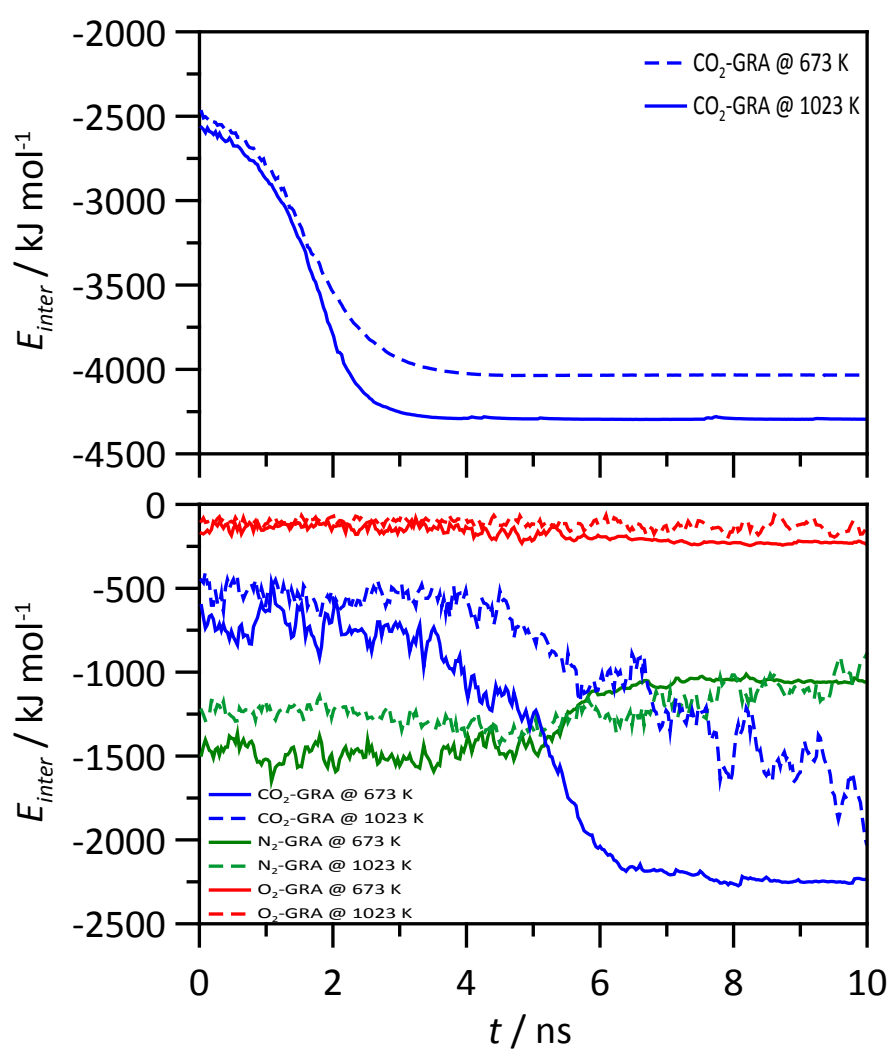

Figure 3. 

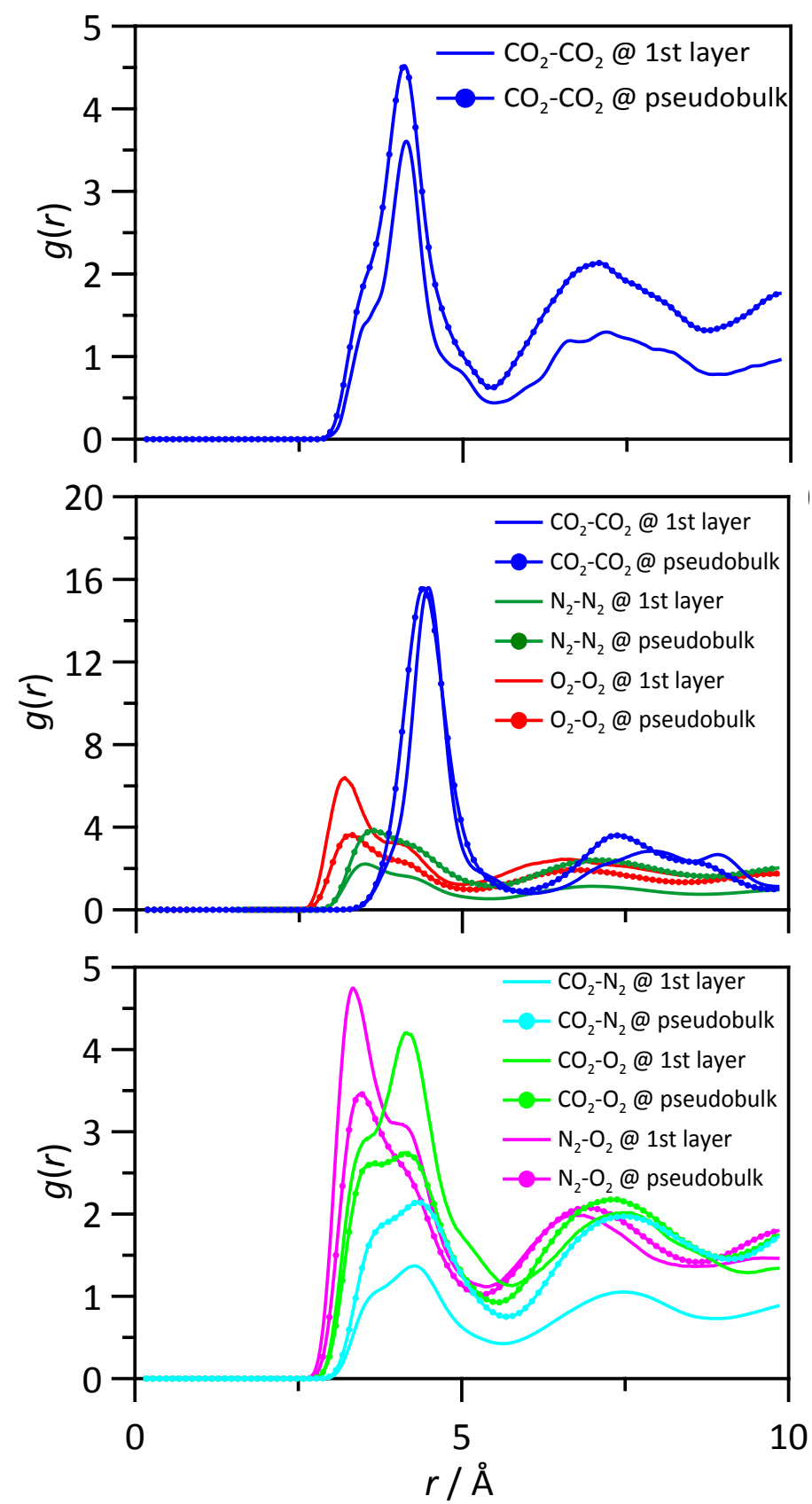

Figure 4. 


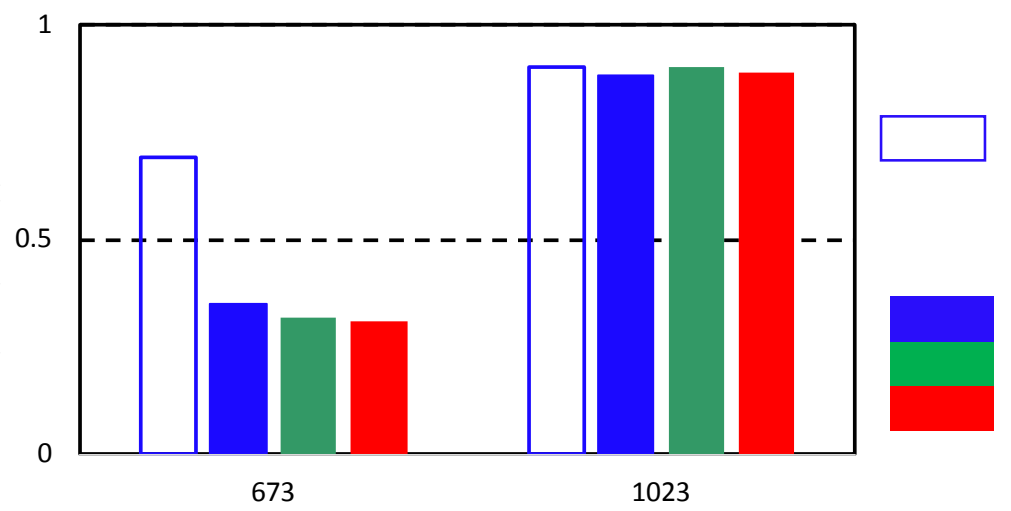

Figure 5. 

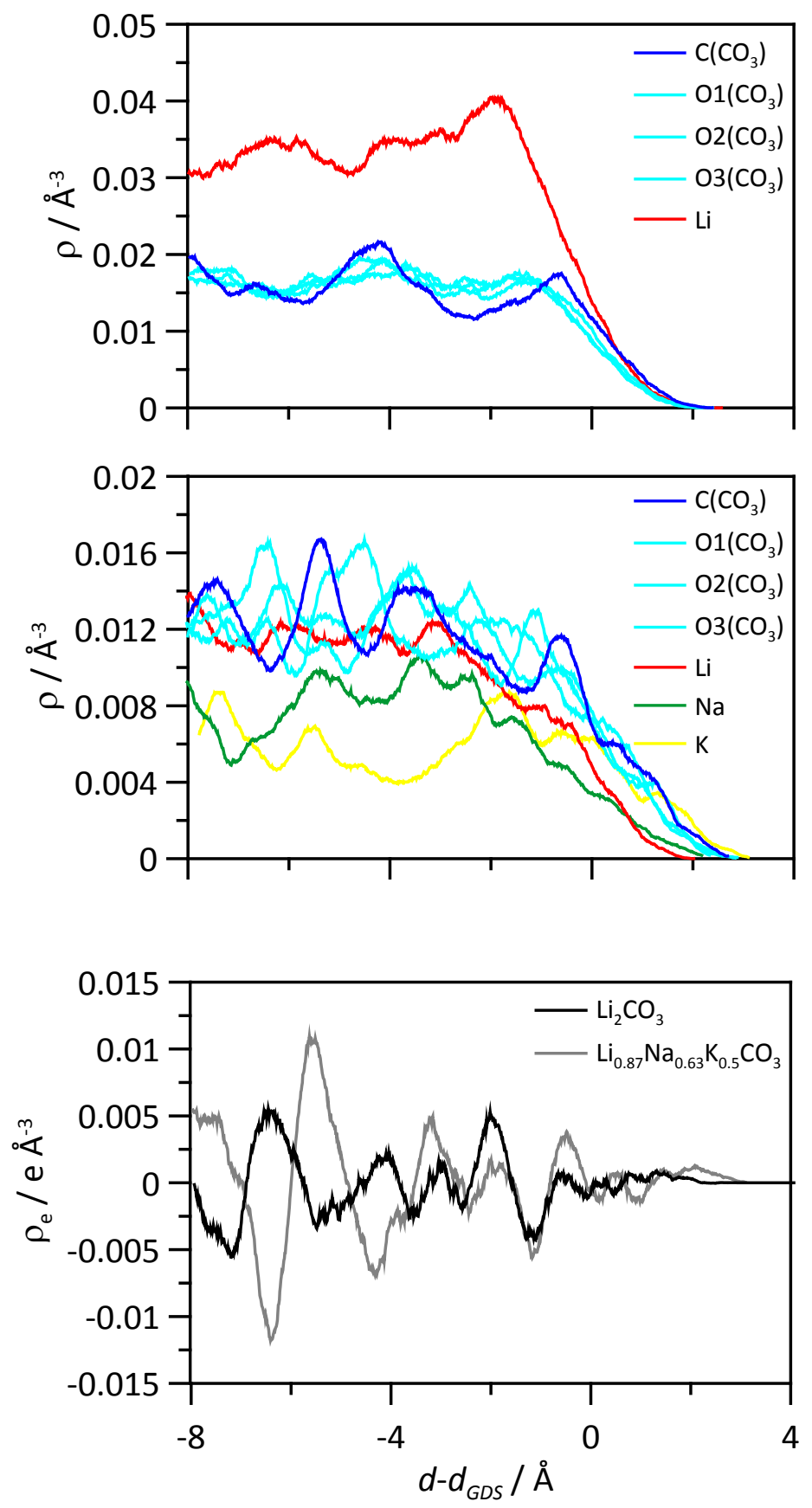

Figure 6. 

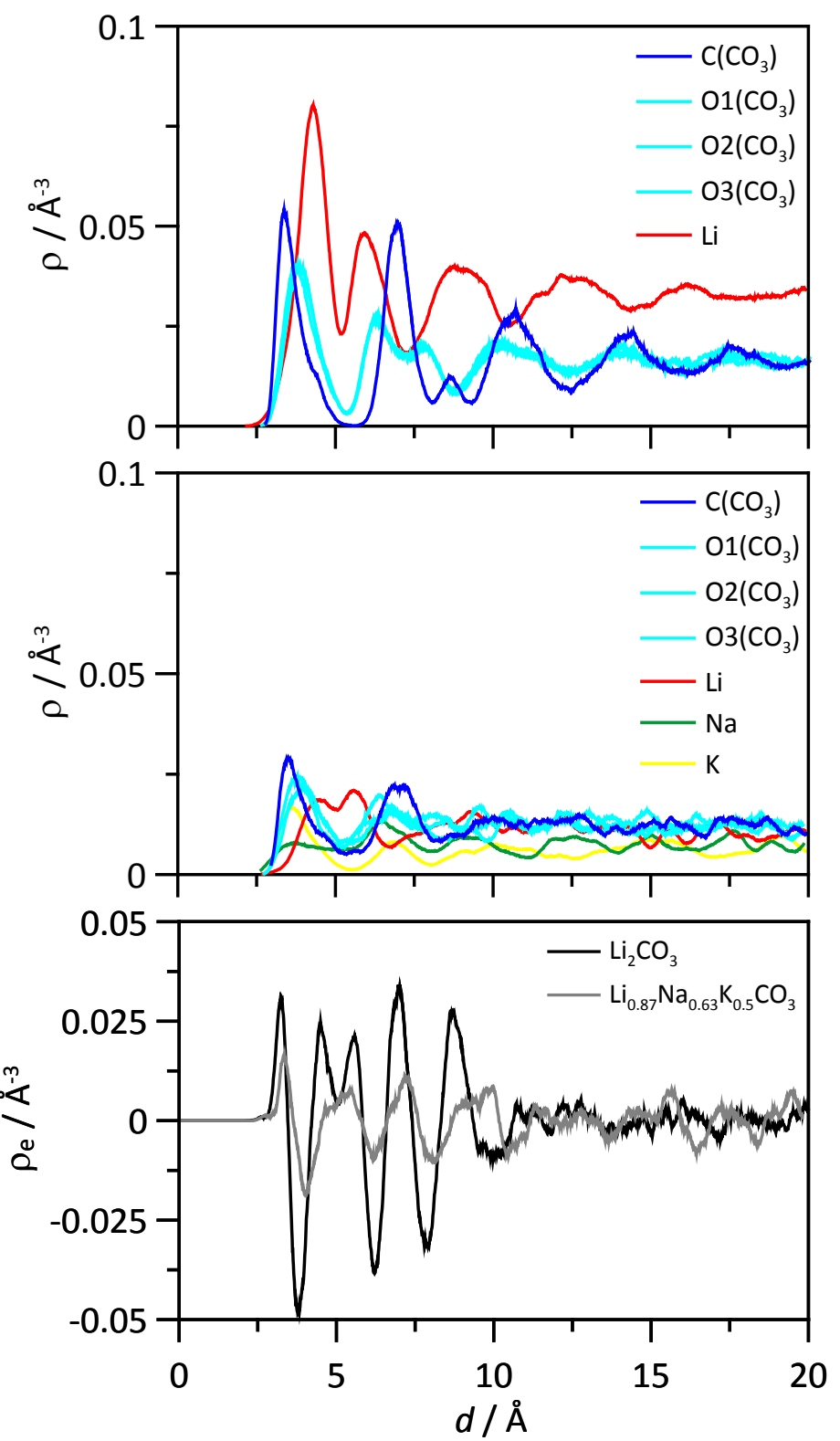

Figure 7. 

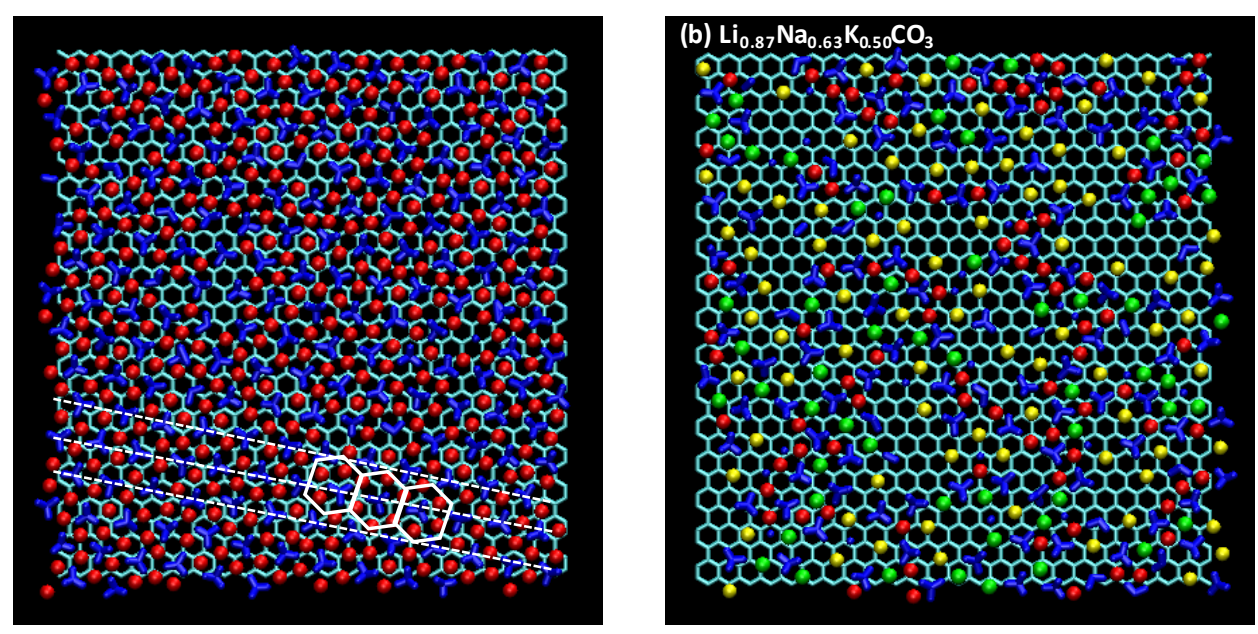

Figure 8. 

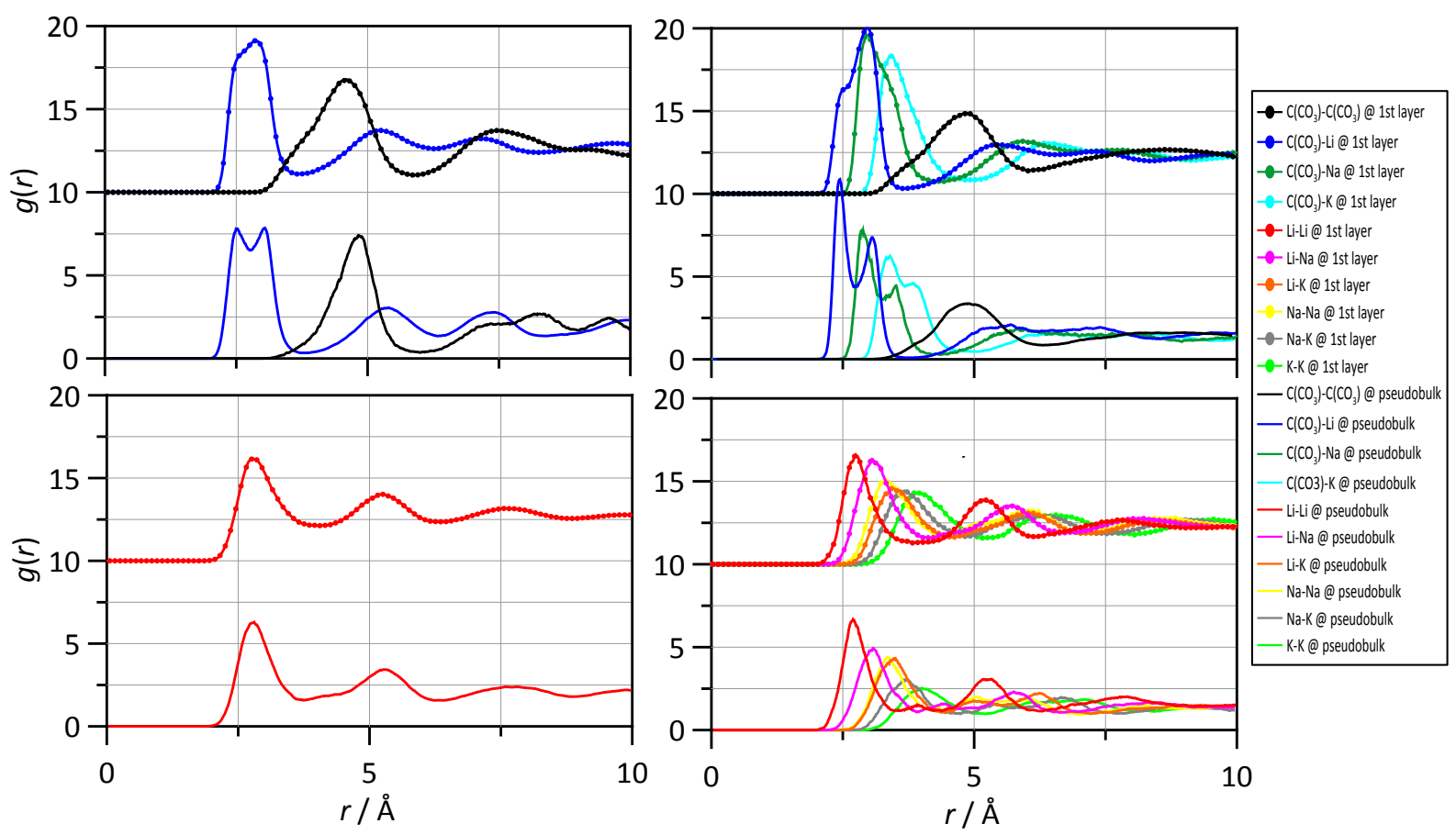

Figure 9. 


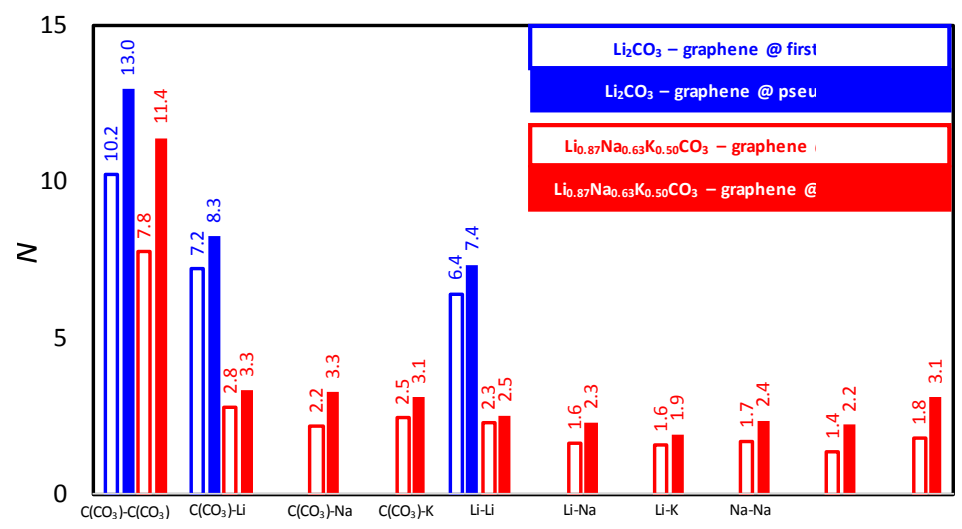

Figure 10. 


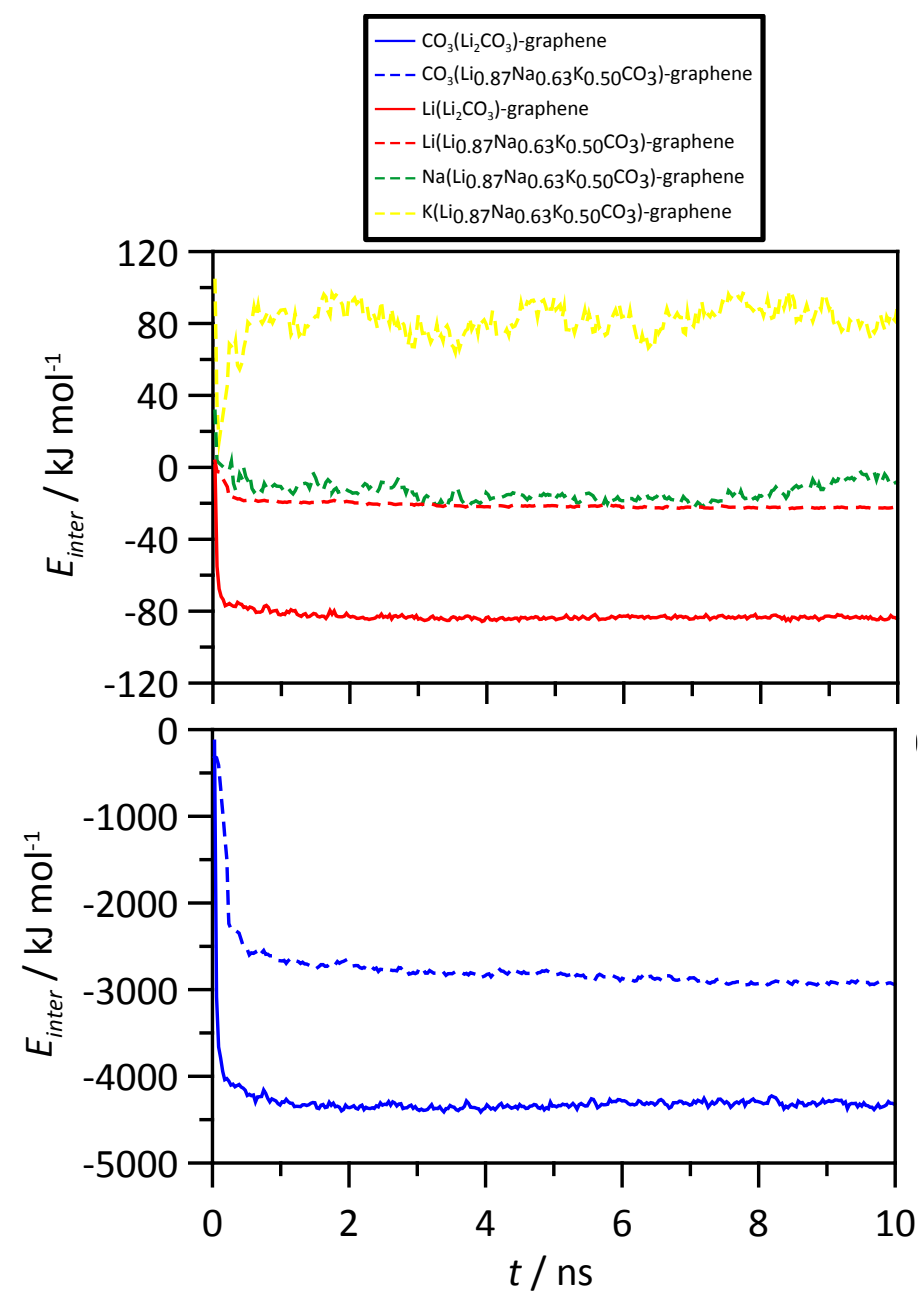

Figure 11. 

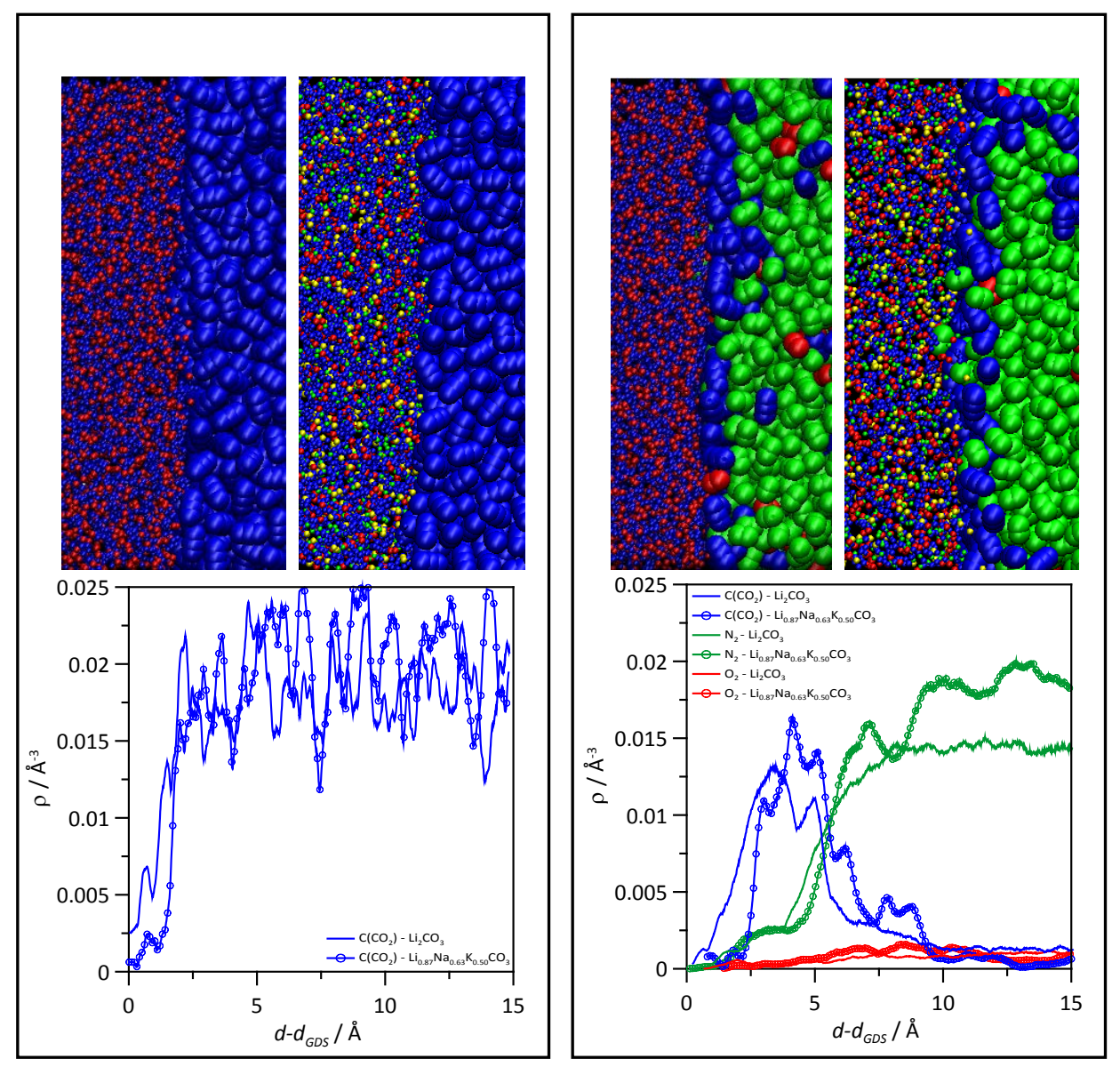

Figure 12. 

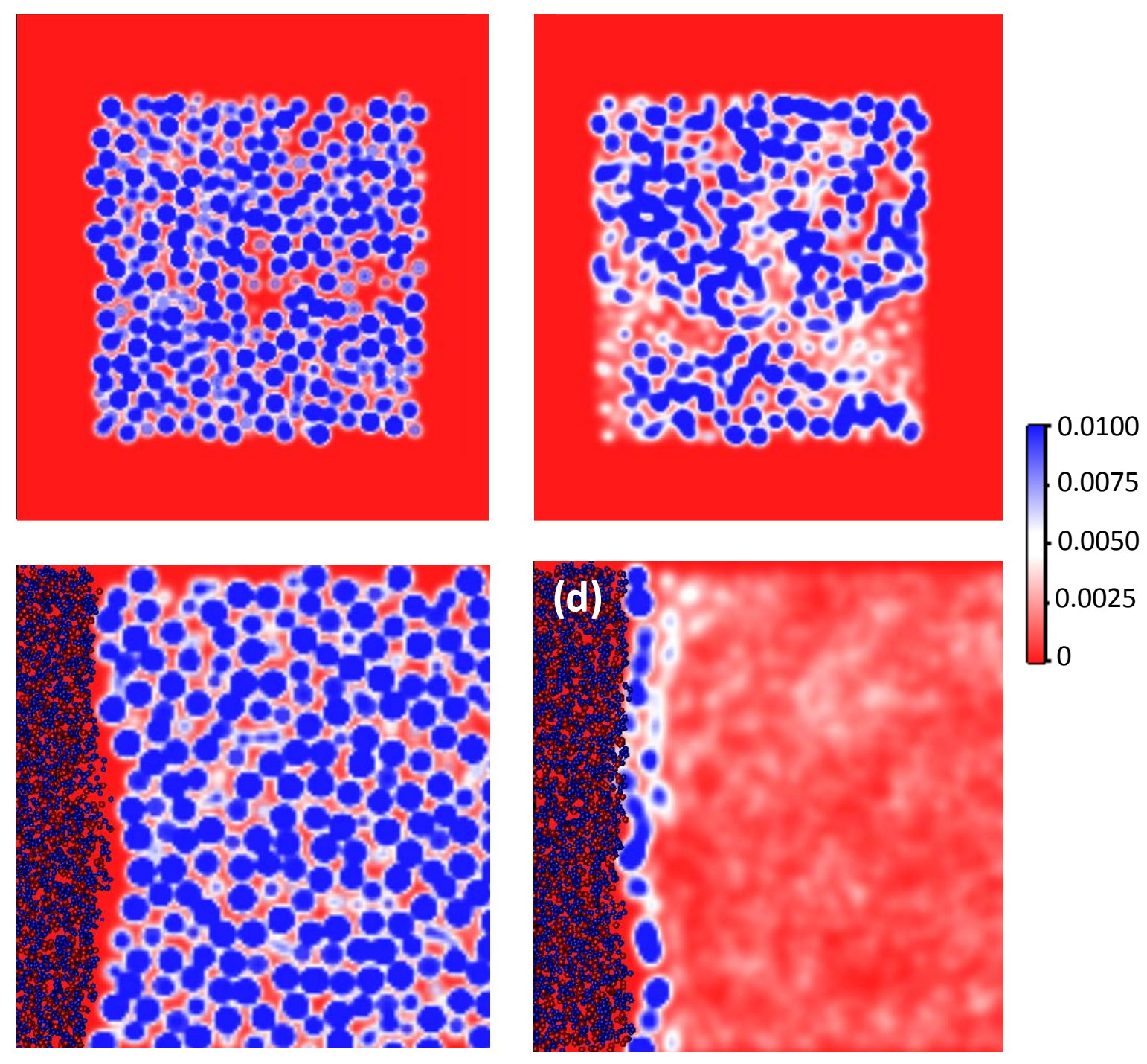

Figure 13. 


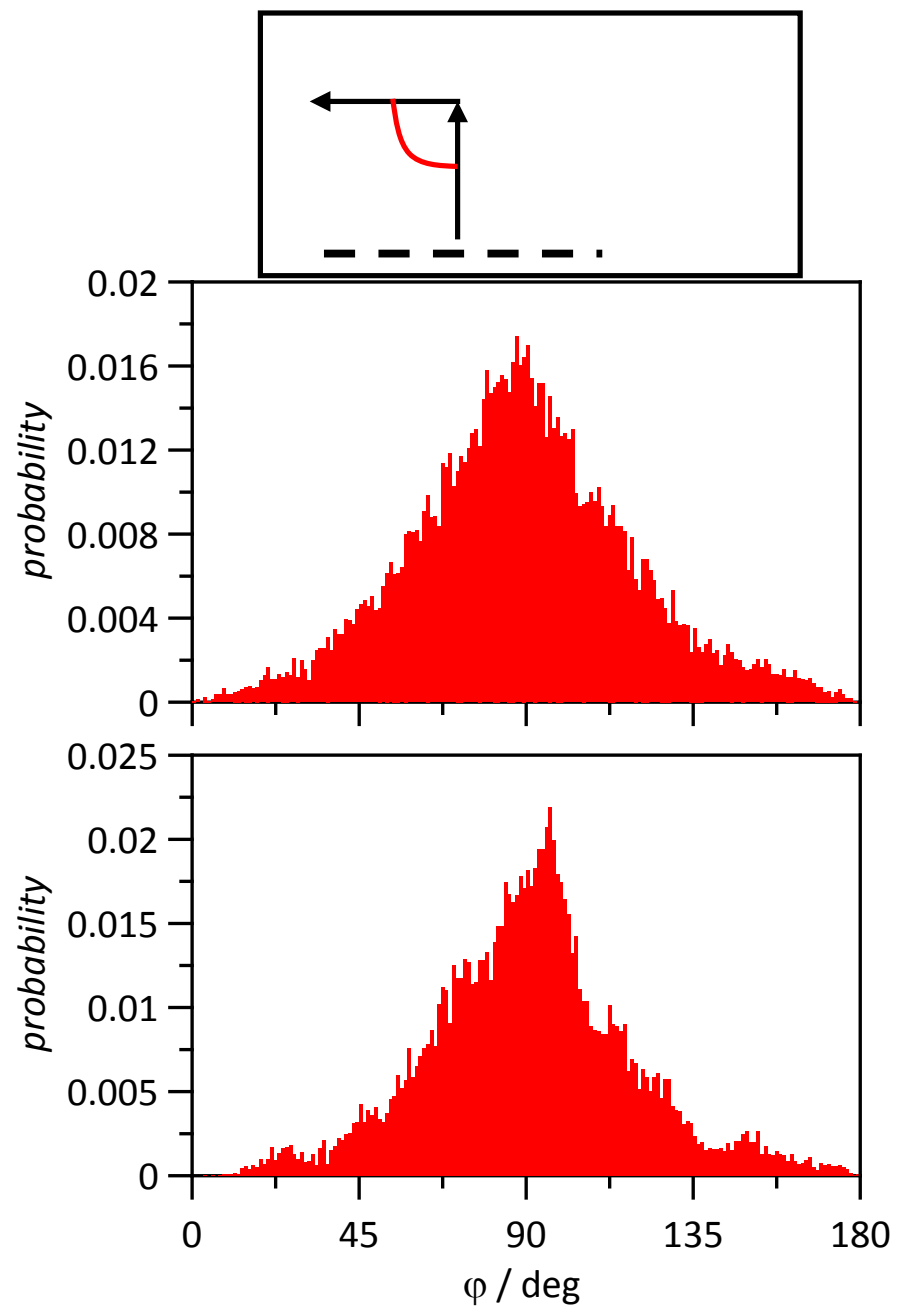

Figure 14. 


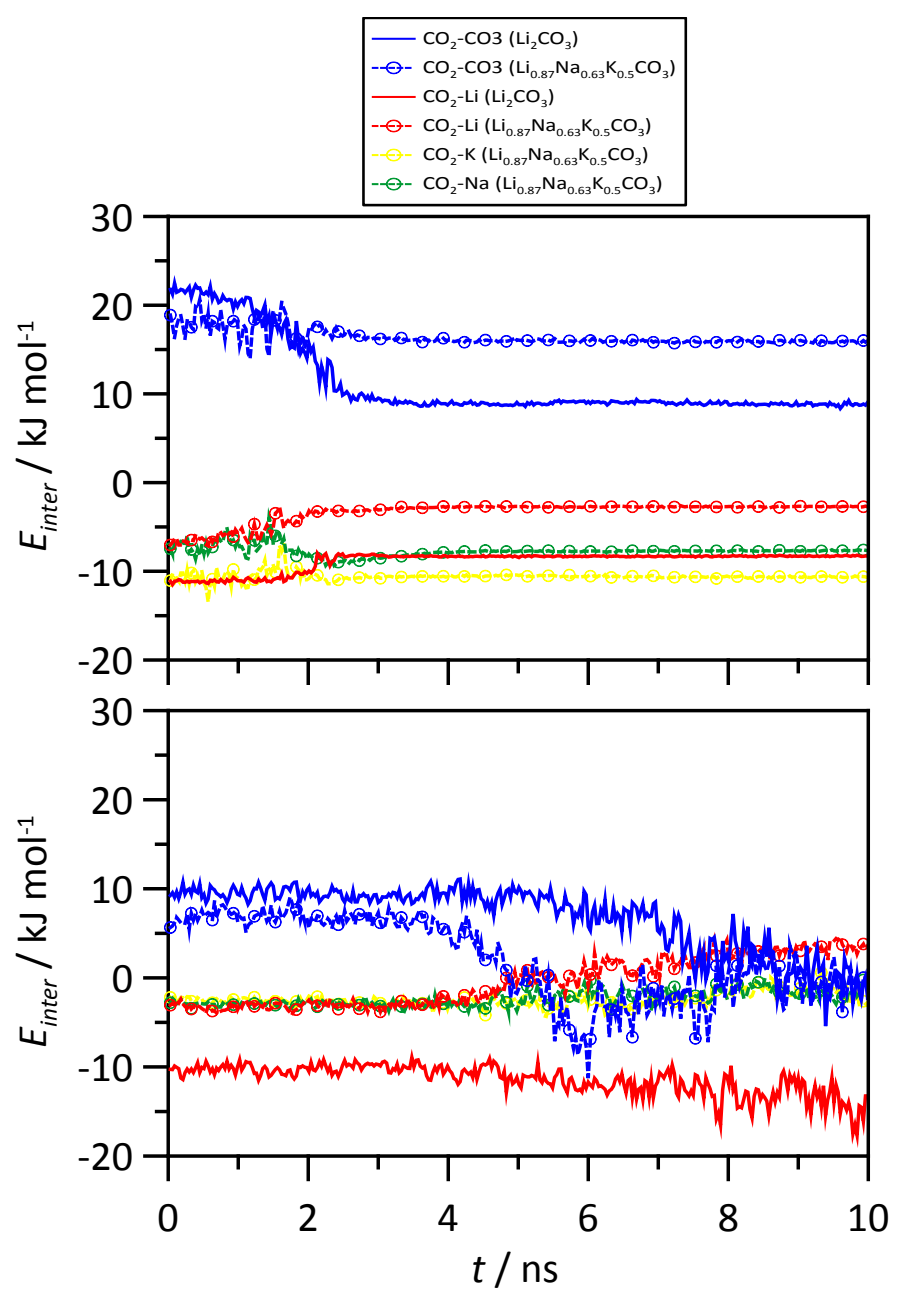

Figure 15. 


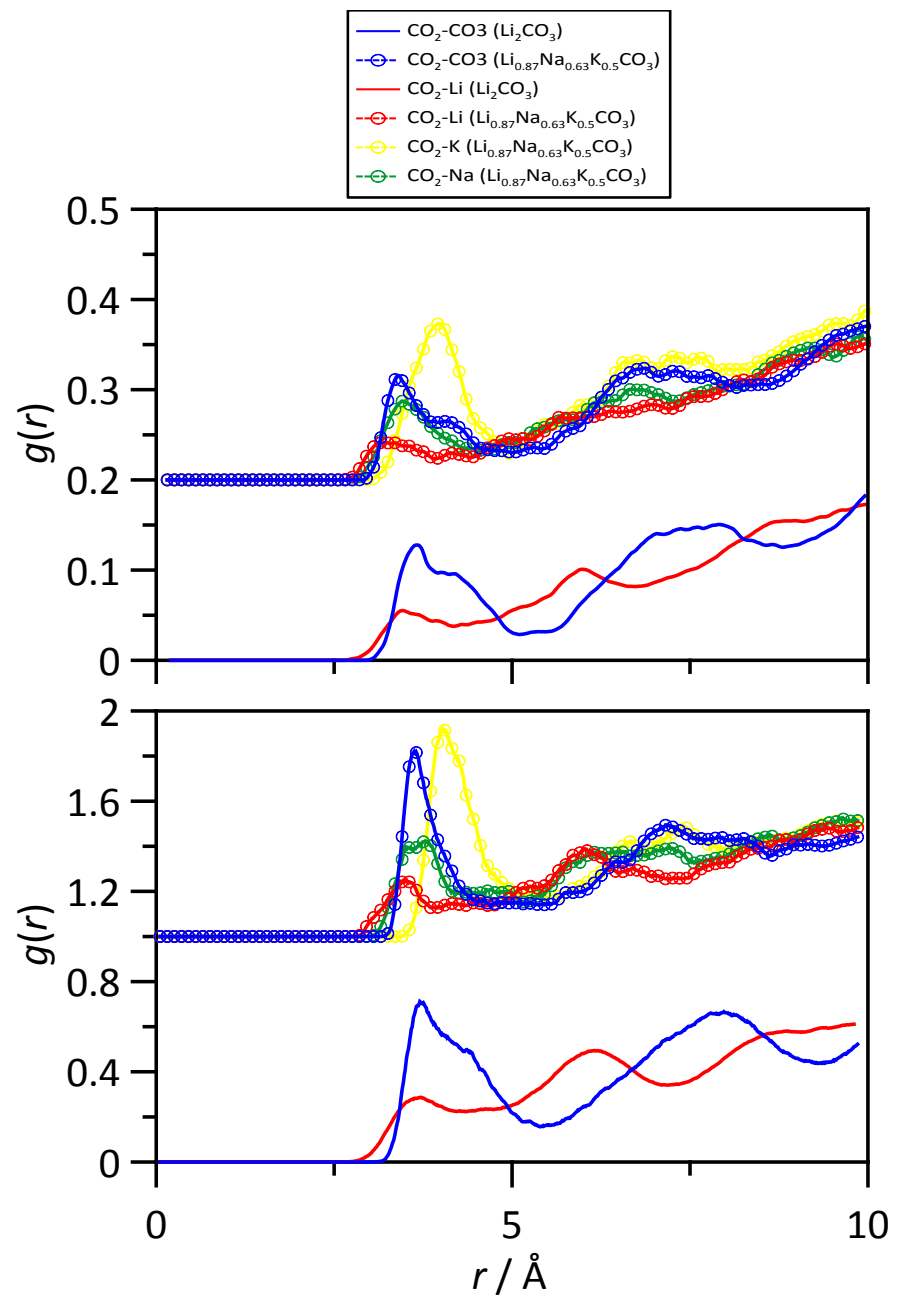

Figure 16. 


\section{REFERENCES}

(1) Lantelme, F.; Groult, H. Molten Salts Chemistry: From Lab to Applications. Elsevier, USA, 2013.

(2) Gaune-Escard, M.; Harberg, G. M. Molten Salts Chemistry and Technology. John Wiley and Sons, UK, 2014.

(3) Serrano-López, R.; Fradera, J.; Cuesta-López, S. Molten Salts Database for Energy Applications. Chem. Eng. Process. 2013, 73, 87-102.

(4) Wang, T.; Mantha, D.; Reddy, R. G. Thermal Stability of the Eutectic Composition in $\mathrm{LiNO}_{3}-\mathrm{NaNO}_{3}-\mathrm{KNO}_{3}$ Ternary System Used for Thermal Energy Storage. Solar Energ. Mat. Sol. C. 2012, 100, 162-168.

(5) Peng, Q.; Wei, X.; Dinag, J.; Yang, X.; Yang, X. High-Temperature Thermal Stability of Molten Salt Materials. Int. J. Energy Res. 2008, 32, 1164-1174.

(6) Vignarooban , K.; Xu, X.; Arvay, Hsu, A.; Kannan, A, M. Heat Transfer Fluids for Concentrating Solar Power Systems - A Review. Appl. Energ. 2015, 146, 383-396.

(7) Pfleger, N.; Bauer, T.; Martin, C.; Eck, M.; Wörner, A. Thermal Energy Storage - Overview and Specific Insight Into Nitrate Salts for Sensible and Latent Heat Storage. Beilstein J. Nanotechnol. 2015, 6, 1487-1497.

(8) Mohn, H.; Wendt, H. Molecular Thermodynamics of Molten Salt Evaporation. Z. Phys. Chem. 1995, 192, 101-119.

(9) Gheribi, A. E.; Torres, J. A.; Chartrand, P. Recommended values for the thermal conductivity of molten salts between the melting and boiling points. Solar Energ. Mat. Sol. C. 2014, 126, 11-25.

(10) Zhao, Q. G.; Hu, C. X.; Liu, S. J.; Guo, H.; Wu, Y. T. The Thermal Conductivity of Molten NaNO3, KNO3 and Their Mixtures. Energy Procedia 2017, 143, 774-779.

(11) An, X.; Chen, J.; Zhang, P.; Tang, Z.; Wang, J. Determination and Evaluation of the Thermophysical Properties of an Alkali Carbonate Eutectic Molten Salt. Faraday Discuss. 2016, 190, 327-338.

(12) Fischer, S.; Leipner, H.; Thümmler, K.; Brendler, E.; Peters, J. Inorganic Molten Salts as Solvents for Cellulose. Cellulose 2003, 10, 227-236.

(13) Frangini, S.; Masi, A. Molten Carbonates for Advanced and Sustainable Energy Applications: Part II. Review of Recent Literature. Int. J. Hydrogen Energ. 2016, 41, 18971-18994.

(14) Nunes, V. M. B.; Queiros, C. S.; Lourenco, M. J. V.; Santos, F. J. V.; Nieto de Castro, C. A.; Molten Salts as Engineering Fluids - A Review: Part I. Molten Alkali Nitrates. Appl. Energ. 2016, 183, 603-611.

(15) Parrado, C.; Marzo, A.; Fuentealba, E.; Fernández, A. G. 2050 LCOE Improvement Using New Molten Salts for Thermal Energy Storage in CSP Plants. Renew. Sus. Energ. Rev. 2016, 57, 505-514.

(16) Vignarooban, K.; Xu, X.; Hsu, K.; Kannan, A. M. Heat Transfer Fluids for Concentrating Solar Power Systems - A Review. Appl. Energ. 2015, 146, 383-396.

(17) Madathil, P. K.; Balagi, N.; Saha, P.; Bharali, J.; Rao, P. V. C.; Choudary, N. V.; Ramesh, K. Preparation and Characterization of Molten Salt Based Nanothermic Fluids with Enhanced Thermal Properties for Solar Thermal Applications. Appl. Therm. Eng. 2016, 109, 901-905.

(18) Frangini, S.; Masi, A. Molten Carbonates for Advanced and Sustainable Energy Applications: Part I. Revisiting Molten Carbonate Properties from a Sustainable Viewpoint. Int. J. Hydrogen Energ. 2016, 41, 18739-18746.

(19) Dicks, A. L. Molten Carbonate Fuel Cells. Curr. Opin. Solid St. M. 2004, 8, 379-383.

(20) Buonomanao, A.; Calise, F.; Ferruzzi, G.; Palombo, A. Molten Carbonate Fuel Cell: An Experimental Analysis of a 1 kW System Fed by Landfill Gas. Appl. Energ. 2015, 140, 146-160.

(21) Mehmeti, A.; Santoni, F.; Della Pietra, M.; McPhail, S. J.; Life Cycle Assessment of Molten Carbonate Fuel Cells: State of the Art and Strategies for the Future. J. Power Sources 2016, 308, 97-108.

(22) Lunghi, P.; Bove, R. Life Cycle Assesment of a Molten Carbonate Fuel Cell Stack. Fuel Cells 2003, 3, 224-230.

(23) Chery, D.; Lair, V.; Cassir, M.; Overview on $\mathrm{CO}_{2}$ Valorization: Challenge of Molten Carbonates. Front. Energy Res. 2015, 3, 43.

(24) Wee, J. H. Carbon Dioxide Emission Reduction Using Molten Carbonate Fuel Cell Systems. Renew. Sust. Energ. Rev. 2014, 32, 178-191.

(25) Forsyth, J.; Lodge, S.; Consonni, S.; Di Bona, D.; Gatti, M.; Martelli, E.; Scaccabarozzi, R.; Vigano, F. Evaluation of Five Alternative $\mathrm{CO}_{2}$ Capture Technologies with Insights to Inform Further Development. Energy Procedia 2017, 114, 2599-2610. 
(26) Olsen, E.; Tomkute, V. Carbon Capture in Molten Salts. Energy Sci. Eng. 2013, 1, 144-150.

(27) Deng, B.; Tang, J.; Mao, X.; Song, Y.; Zhu, H.; Xiao, W.; Wang, D. Kinetic and Thermodynamic Characterization of Enhanced Carbon Dioxide Absorption Process with Lithium Oxide-Containing Ternary Molten Carbonate. Environ. Sci. Technol. 2016, 50, 10588-10595.

(28) Patricio, S. G.; Papaioannou, E. I.; Ray, B. M.; Metcalfe, I. S.; Marques, F. M. B. Composite $\mathrm{CO}_{2}$ Separation Membranes: Insights on Kinetics and Stability. J. Membrane Sci. 2017, 541, 253-261.

(29) Näfe, H. Composite $\mathrm{CO}_{2}$ Separation Membranes: Insights on Kinetics and Stability. ECS Solid State Sci. Technol. 2014, 3, N23-N29.

(30) Yang, Z.; Zhu, Y.; Han, M. Synthesis and Characterization of Gadolinium Doped Ceria-Carbonate DualPhase Membranes for Carbon Dioxide Separation. J. Alloy Comp. 2017, 723, 70-74.

(31) Liu, H.; Dai, S.; Jiang, D. E. Insights into $\mathrm{CO}_{2} / \mathrm{N}_{2}$ Separation Through Nanoporous Graphene from Molecular Dynamics. Nanoscale 2013, 5, 9984-9987.

(32) Park, H. B. Graphene - Based Membranes - A New Opportunity for $\mathrm{CO}_{2}$ Separation. Carbon Management 2014, 5, 251-253.

(33) Yoon, H. W.; Cho, Y. H.; Park, H. B. Graphene - Based Membranes: Status and Prospects. Phil. Trans. R. Soc. A 2016, 374, 20150024.

(34) Li, W.; Zheng, X.; Dong, Z.; Li, C.; Wang, W.; Yan, Y.; Zhang, J. Molecular Dynamics Simulations of CO2/N2 Separation through Two-Dimensional Graphene Oxide Membranes. J. Phys. Chem. C 2016, 120, 2606126066.

(35) Tamilarasa, P.; Ramaprabhu, S. Integration of Polymerized Ionic Liquid with Graphene for Enhanced $\mathrm{CO}_{2}$ Adsorption. J. Mater. Chem. A 2015, 3, 101-108.

(36) Tamilarasan, P.; Ramaprabhu, S. Amine-rich Ionic Liquid Grafted Graphene for Subambient Carbon Dioxide Adsorption. RSC Adv. 2016, 6, 3032-3040.

(37) Hu, L.; Song, Y.; Jiao, S.; Liu, Y.; Ge, J.; Jiao, H.; Zhu, J.; Wang, J., Zhu, H.; Fray, D. J. Direct Conversion of Greenhouse Gas CO2 into Graphene via Molten Salts Electrolysis. ChemSusChem 2016, 9, 588-594.

(38) Wu, H.; Li, Z.; Ji, D.; Liu, Y.; Yi, G.; Yuan, D.; Wang, B.; Zhang, Z. Effect of molten carbonate composition on the generation of carbon material. RSC Adv. 2017, 7, 8467-8473.

(39) Roest, D. L.; Ballone, P.; Bedeaux, D.; Kjelstrup, S. Molecular Dynamics Simulations of Metal/Molten Alkali Carbonate Interfaces. J. Phys. Chem. C 2017, 121, 17827-17847.

(40) Lee, K. J.; Kim, S. J. Theoretical Investigation of CO2 Adsorption on Graphene. Bull. Korean Chem. Soc. 2013, 34, 3022-3026.

(41) Takeuchi, K.; Yamamoto, S.; Hamamoto, Y.; Shiozawa, Y.; Tashima, K.; Fukidome, H.; Koitaya, T.; Mukai, K.; Yoshimoto, S.; Suemitsu, M.; Morikawa, Y.; Yoshinobu, J.; Matsuda, I. Adsorption of CO2 on Graphene: A Combined TPD, XPS, and vdW-DF Study. J. Phys. Chem. C 2017, 121, 2807-2814.

(42) Lyubartsev, A. P.; Laaksonen, A. MDynaMix - A Scalable Portable Parallel MD Simulation Package for Arbitrary Molecular Mixtures. Comput. Phys. Commun. 2000, 128, 565-589.

(43) Aparicio, S.; Atilhan, M. Molecular Dynamics Study of Carbon Nanostructures in N-Methylpiperazinium Lactate Ionic Liquid. J. Phys. Chem. C 2013, 117, 22046-22059.

(44) Chen, C.; Tran, T.; Olivares, R.; Wright, S.; Sun, S. Coupled Experimental Study and Thermodynamic Modelling And Thermal Stabilty of $\mathrm{L}_{2} \mathrm{CO}_{3}-\mathrm{Na}_{2} \mathrm{CO}_{3}-\mathrm{K}_{2} \mathrm{CO}_{3}$ Based Salts. J. Solar Energ. T. ASME 2014, 136, 031017.

(45) Martínez, L.; Andrade, R.; Birgin, E. G.; Martínez, J. M. Packmol: A Package for Building Initial Configurations for Molecular Dynamics Simulations. J. Comput. Chem. 2009, 30, 2157-2164.

(46) Kahng, Y. H.; Lee, S.; Park, W.; Jo, G.; Choe, M.; Lee, J. H.; Yu, H.; Lee, T.; Lee, K. Thermal Stability of Multilayer Graphene Films Synthesized by Chemical Vapor Deposition and Stained by Metallic Impurities. Nanotechnology 2012, 23, 075702.

(47) Wang, J.; Huang, J.; Yan, R.; Wang, F.; Cheng, W.; Guo, Q.; Wang, J. Graphene Microsheets from Natural Microcrystalline Graphite Minerals: Scalable Synthesis and Unusual Energy Storage. J. Mater. Chem. A 2015, 3, 3144-3150.

(48) Tuckerman, M.; Berne, B. J.; Martyna, G. J. Reversible Multiple Time Scale Molecular Dynamics. J. Chem. Phys. 1992, 97, 1990-2001.

(49) Ohba, T.; Takase, A.; Ohyama, Y.; Kanoh, H. Grand Canonical Monte Carlo Simulations of Nitrogen Adsorption on Graphene Materials with Varying Layer Number. Carbon 2013, 61, 40-46.

(50) Kislenko, S. A.; Samoylov, I. S.; Amirov, R. H. Molecular Dynamics Simulation of the Electrochemical Interface Between a Graphite Surface and the Ionic Liquid [BMIM][PF 6 . Phys. Chem. Chem. Phys. 2009, 11, 5584-5590. 
(51) Trinh, T. T.;Vlugt, T. J. H.; Hägg, M. B.; Bedeaux, D.; Kjelstrup, S. Selectivity and Self-Diffusion of $\mathrm{CO}_{2}$ and $\mathrm{H}_{2}$ in a Mixture on a Graphite Surface. Front. Chem. 2013, 1, 38.

(52) Méndez-Morales, T.; Carrete, J.; Pérez-Rodríguez, M.; Cabeza, O.; Gallego, L. J.; Lynden-Bell, R.; Varela, L. M. Molecular Dynamics Simulations of the Structure of the Graphene-Ionic Liquid/Alkali Salt Mixtures Interface. Phys. Chem. Chem. Phys. 2014, 16, 13721-13728.

(53) Gómez-González, V.; Docampo-Álvarez, B.; Méndez-Morales, T.; Cabeza, O.; Ivanistsev, V. B.; Fedorov, M. V.; Gallego, L. J.; Varela, L. M. Molecular Dynamics Simulation of the Structure and Interfacial Free Energy Barriers of Mixtures of Ionic Liquids and Divalent Salts Near a Graphene Wall. Phys. Chem. Chem. Phys. 2017, 19, 846-853.

(54) Begic, S.; Jonnsson, E.; Chen, F.; Forsyth, M. Molecular Dynamics Simulations of Pyrrolidinium and Imidazolium Ionic Liquids at Graphene Interfaces. Phys. Chem. Chem. Phys. 2017, 19, 30010-30020. 


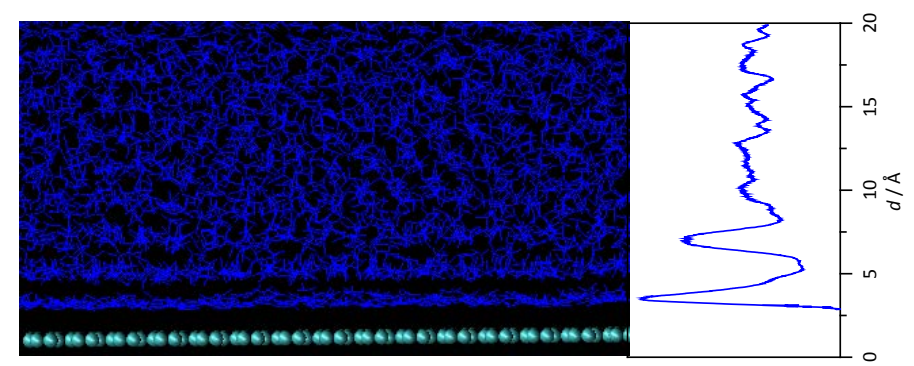

Table of Contents Graphic 